\title{
Minimum entropy generation due to heat transfer and fluid friction in a parabolic trough receiver with non-uniform heat flux at different rim angles and concentration ratios
}

\author{
Aggrey Mwesigye ${ }^{1,2}$, Tunde Bello-Ochende ${ }^{2 \dagger}$, Josua P. Meyer ${ }^{1}$ \\ ${ }^{1}$ Department of Mechanical and Aeronautical Engineering, University of Pretoria \\ Private Bag X20, Hatfield 0028, South Africa \\ ${ }^{2}$ Department of Mechanical Engineering, Tshwane University of Technology, \\ Private Bag X680, Pretoria, 0001, South Africa \\ ${ }^{3}$ Department of Mechanical Engineering, University of Cape Town \\ Private Bag X3, Rondebosch, 7701, South Africa
}

\begin{abstract}
In this paper, Monte Carlo ray-tracing and computational fluid dynamics are used to numerically investigate the minimum entropy generation due to heat transfer and fluid friction in a parabolic trough receiver. The analysis was carried out for rim angles in the range $40^{\circ}-120^{\circ}$, concentration ratios in the range $57-143$, Reynolds numbers in the range $1.02 \times 10^{4}-1.36 \times 10^{6}$ and fluid temperatures in the range $350-650 \mathrm{~K}$. Results show existence of an optimal Reynolds number at any given combination of fluid temperature, concentration ratio and rim angle for which the total entropy generation is a minimum. The total entropy generation was found to increase as the rim angle reduced, concentration ratio increased and fluid temperature reduced. The high entropy generation rates at low rim angles are mainly due to high peak temperatures in the absorber tube at these low rim angles.
\end{abstract}

Keywords: Concentration ratio, Entropy generation, Monte Carlo ray-tracing, Parabolic trough, Receiver, Rim angle

\footnotetext{
${ }^{\dagger}$ Corresponding author $\quad$ Tel.: +27 21 650-3673; fax: +27 21 650-3240

E-mail address: tunde.bello-ochende@uct.ac.za, josua.meyer@up.ac.za
} 


\section{Nomenclature}

$a_{c} \quad$ Collector's aperture width, m

$A_{a} \quad$ Collector's aperture area, $\mathrm{m}^{2}$

$A_{r} \quad$ Projected absorber tube area, $\mathrm{m}^{2}$

Be Bejan Number $=$ entropy generated due to heat transfer/total entropy generated

$C_{1}, C_{2}, C_{\mu} \quad$ Turbulent model constants

$c_{p} \quad$ Specific heat capacity, $\mathrm{J} \mathrm{kg}^{-1} \mathrm{~K}^{-1}$

$C_{R} \quad$ Concentration ratio

$d_{g i} \quad$ Glass cover inner diameter, $\mathrm{m}$

$d_{g o} \quad$ Glass cover outer diameter, $\mathrm{m}$

$d_{r i} \quad$ Absorber tube inner diameter, $\mathrm{m}$

$d_{\text {ro }} \quad$ Absorber tube outer diameter, $\mathrm{m}$

DNI Direct normal Irradiance, $\mathrm{W} / \mathrm{m}^{2}$

$G_{k} \quad$ Generation of turbulence kinetic energy due to mean velocity gradients, $\mathrm{kg} \mathrm{m}^{-1} \mathrm{~s}^{-3}$

$h_{w} \quad$ Wind heat transfer coefficient, $\mathrm{W} \mathrm{m} \mathrm{m}^{-2} \mathrm{~K}^{-1}$

$k \quad$ Turbulent kinetic energy, $\mathrm{m}^{2} \mathrm{~s}^{-2}$

L Length, $\mathrm{m}$

p Pressure, $\mathrm{Pa}$

Re Reynolds number

$S \quad$ Modulus of the mean rate-of-strain tensor, $\mathrm{s}^{-1}$

$S_{i j} \quad$ Rate of linear deformation tensor, $\mathrm{s}^{-1}$

$S_{\text {gen }} \quad$ Entropy generation rate due to heat transfer and fluid friction in the receiver, $\mathrm{W} / \mathrm{K}$

$S_{\text {gen }}^{\prime} \quad$ Entropy generation due to heat transfer and fluid friction per unit length of the receiver, $\mathrm{W} / \mathrm{mK}$

$S^{\prime \prime \prime}{ }_{\text {gen }} \quad$ Volumetric entropy generation, $\mathrm{W} \mathrm{m}{ }^{-3} \mathrm{~K}^{-1}$

$\left(S^{\prime \prime \prime}{ }_{\text {gen }}\right)_{F} \quad$ Volumetric entropy generation due to fluid friction, $\mathrm{W} \mathrm{m}{ }^{-3} \mathrm{~K}^{-1}$

$\left(S^{\prime \prime \prime}{ }_{g e n}\right)_{H} \quad$ Volumetric entropy generation due to heat transfer, $\mathrm{W} \mathrm{m}^{-3} \mathrm{~K}^{-1}$

$S_{P R O D, V D}^{\prime \prime \prime} \quad$ Entropy production by direct dissipation, $\mathrm{W} \mathrm{m} \mathrm{m}^{-3} \mathrm{~K}^{-1}$

$S_{P R O D, T D}^{\prime \prime} \quad$ Entropy production by turbulent dissipation, $\mathrm{W} \mathrm{m}{ }^{-3} \mathrm{~K}^{-1}$

$S_{\text {PROD,T }}^{\prime \prime \prime} \quad$ Entropy production by heat transfer with mean temperatures, $\mathrm{W} \mathrm{m}^{-3} \mathrm{~K}^{-1}$

$S_{P R O D, T G}^{\prime \prime \prime} \quad$ Entropy production by heat transfer with fluctuating temperatures, $\mathrm{W} \mathrm{m}{ }^{-3} \mathrm{~K}^{-1}$ 


$\begin{array}{ll}T & \text { Temperature, } \mathrm{K} \\ V & \text { Volume, } \mathrm{m}^{3} \\ V_{w} & \text { Wind velocity, } \mathrm{m} / \mathrm{s} \\ \dot{V} & \text { Volumetric flow rate, } \mathrm{m}^{3} / \mathrm{s} \\ u_{i}, u_{j} & \text { Time averaged velocity components, } \mathrm{m} \mathrm{s}^{-1} \\ u^{\prime}, v^{\prime}, w^{\prime} & \text { Velocity fluctuations, } \mathrm{m} \mathrm{s}^{-1} \\ u_{\tau} & \text { Friction velocity }\left(\mu_{\tau}=\sqrt{\tau_{w} / \rho}\right), \mathrm{m} \mathrm{s}^{-1} \\ x_{i}, x_{j} & \text { Spatial coordinates, } \mathrm{m} \\ x, y, z & \text { Cartesian coordinates, } \mathrm{m} \\ y^{+} & \text {Dimensionless wall coordinate } \\ -\rho \overline{u_{i}^{\prime} u_{j}^{\prime}} & \text { Reynolds stresses, } \mathrm{Nm}^{-2}\end{array}$

Greek letters

$\tilde{\alpha}$

$\alpha$

$\alpha_{t}$

$\sigma_{h . t}$

$\sigma_{\varepsilon}$

$\sigma_{k}$

$\delta_{i j}$

$\varepsilon$

$\xi$

$\eta$

$\eta_{c}$

$\varphi_{r}$

$\rho$

$\rho$

$\tau_{g}$

$\tau_{w}$

$\theta$

$\lambda$

$\lambda_{e f f}$

$\mu$
Absorber tube absorptivity

Thermal diffusivity, $\mathrm{m}^{2} \mathrm{~s}^{-1}$

Turbulent thermal diffusivity, $\mathrm{m}^{2} \mathrm{~s}^{-1}$

Turbulent Prandtl number for energy

Turbulent Prandtl number for $\varepsilon$

Turbulent Prandtl number for $k$

Kronecker delta

Turbulent dissipation rate, $\mathrm{m}^{2} \mathrm{~s}^{-3}$

Emissivity

Turbulence model parameter $=S k / \mathcal{E}$

Collector thermal efficiency, \%

Collector rim angle

Density, $\mathrm{kg} \mathrm{m}^{-3}$

Collector reflectivity

Glass cover transimissivity

Wall shear stress, $\mathrm{N} / \mathrm{m}^{2}$

Absorber tube circumference angular position, degrees

Fluid thermal conductivity, $\mathrm{Wm}^{-1} \mathrm{~K}^{-1}$

Heat transfer fluid effective thermal conductivity, $\mathrm{Wm}^{-1} \mathrm{~K}^{-1}$

Viscosity, Pa s 
$\mu_{t}$

$\mu_{\text {eff }}$

$v$

\section{Subscripts}

$a m b$

$c$

$g$

inlet

$i, j, k$

sky

$t$

w

Super scripts

Fluctuation from mean value
Eddy viscosity, Pa s

Effective viscosity, $\mathrm{Pa} \mathrm{s}$

Kinematic viscosity, $\mathrm{m}^{2} \mathrm{~s}^{-1}$
Ambient

Collector

Glass cover

Absorber tube inlet

General spatial indices

Sky

Turbulent

Wall 


\section{Introduction}

Increasing world's population as well as increasing urbanisation rates are increasingly putting pressure on the available resources. This together with concerns of climate change due global warming means that available resources must be utilised in a sustainable way and with minimum impacts on the environment. As far as provision of clean and sustainable energy is concerned, several efforts by both governments and private entities have been directed towards development and deployment of clean and renewable energy systems.

Solar energy is one of the renewable energy sources that is widely available and has significant potential to provide a significant portion of the global energy needs. Many technologies have been developed for conversion of the sun's energy into useful forms, with concentrated solar power systems being the widely used for large-scale electricity generation [1]. Concentrated solar systems in use today include parabolic trough systems, solar dish, linear Fresnel systems and solar towers. The parabolic trough systems are the most commercially and technically developed systems in use today. They produce the largest share of electricity available from concentrated solar thermal systems today [2].

Several studies on analysis of parabolic trough collector systems are available in literature such as Refs. [3-12]. Research on parabolic trough systems entails almost every aspect of the technology ranging from development of highly reflective coatings for the collector, selective coatings for the receiver's absorber tube, development of heat transfer fluids, cost reduction measures and others $[6,13,14]$.

The parabolic trough's linear receiver is a central component to the performance of the entire system. As such, the linear receiver has been the focus of several investigations regarding its thermal performance and how its performance can be improved [3,4,6,7,15-19]. The state and design of the receiver significantly affects the thermal performance of the systems.

In most studies on the performance analysis of parabolic trough receivers, the basis of analysis is mainly the first law of thermodynamics and therefore does not give an understanding of the quality of energy from the parabolic trough systems. Application of the second law is usually recommended if one is to understand the quality of energy from a given system and for the eventual thermodynamic optimisation of the thermal system and system components [20,21]. In the second law of thermodynamics, the entropy generation rates are determined and the minimisation of the entropy generated improves the thermodynamic performance of the system components and the entire system. This method has been termed 
the entropy generation minimisation method [21]. Several researchers have applied the entropy generation minimisation method to the analysis and optimisation of engineering systems [8,22,23] as well as to heat transfer and fluid flow problems [24-27]. Moreover, the entropy generation minimisation method has been shown to be applicable to a wide range of engineering systems such as small-scale wood fired circulating fluidised bed adiabatic combustor as demonstrated in the study by Baloyi et al. [28], analysis of exergy recovery from the exhaust cooling in a DI diesel engine as demonstrated by Ghazikhani et al. [29] and in characterising the effects of fuel additives on exergy parameters of engines [30] and many others.

For parabolic trough systems, studies on entropy generation are not wide spread. An analytical method suggested by Bejan [21] for determining the entropy generation in solar collectors was adapted to concentrating collectors by Kalogirou [31]. In this method, the entropy generation is a function of the incident solar radiation, useful heat delivered to the user and the receiver heat loss. In our previous study [25], we showed that the entropy generation due to heat transfer and fluid friction inside the receiver's absorber tube gives nearly the same optimum flow rates as the analytical method [31]. The method used in our previous investigation [25] directly calculates the entropy generation using computational fluid dynamics according to the equations derived by Kock and Herwig [32].

In the analytical method for determining entropy generation in the parabolic trough collector [21,31], the effect of several collector parameters on entropy generation is not explicitly considered. Moreover, in our previous investigation [25], the effect of rim angles on entropy generation was not investigated and the heat flux profile used was an approximate one. Therefore, this study seeks to determine minimum entropy generation rates in a parabolic receiver taking into consideration the actual heat flux profile on the receiver's absorber tube and the effect of rim different rim angles and concentration ratios. In this study, the actual heat flux profiles on the receiver are determined using Monte Carlo ray - tracing and used as a boundary condition in the computational fluid dynamics analysis. The entropy generation rates are also determined locally from the temperature and velocity fields obtained from the computational fluid dynamics analysis.

\section{Physical model}

Fig. 1 shows 3-D model of the parabolic trough collector system. Fig. 2 shows the 2-D views of the parabolic trough receiver. The receiver consists of a steel absorber tube with a selective 
coating for high absorption of solar radiation and low emission of infrared radiation. A glass cover encloses the absorber tube and the annulus space evacuated to suppress convection heat loss [6]. Because of symmetry, only half of the receiver $\left(-90^{\circ} \leq \theta \leq 90^{\circ} ; 0 \leq \mathrm{z} \leq L\right)$ was considered.

The geometrical parameters for the considered receiver are shown in Table 1.0

\section{Ray tracing}

In Monte Carlo ray tracing, a number of rays is selected and traced as they undergo several optical interactions. For purposes of this study, SolTrace, a software tool developed by the National Renewable Energy Laboratory for modelling concentrated solar power system was used [33]. The ray tracing procedure involves specification of sun's shape, the geometries of the collector and the receiver and the optical properties of the collector and the receiver. A maximum number of rays to be generated by the sun are then selected and desired number of ray intersections specified. The rays are then traced as they are reflected by the reflecting mirror, transmitted by the glass cover and absorbed by the absorber tube. A sample of ray intersection obtained from SolTrace is shown in Fig. 3(a) for a rim angle of $80^{\circ}$ and aperture width of $10 \mathrm{~m}$ and Fig. 3(b) for a rim angle of $40^{\circ}$ and an aperture width of $10 \mathrm{~m}$.

The sample heat flux distribution obtained from ray tracing is shown in Fig. 4(a) for rim angles of $80^{\circ}$ and $120^{\circ}$ and an aperture width of $6 \mathrm{~m}$ or concentration ratio( $\left(\mathrm{C}_{\mathrm{R}}\right)$ of 86 . In Fig. 4(a), the receiver's absorber tube circumference is spread and the angles of $0^{\circ}$ and $360^{\circ}$ shown in Fig. 4(a) correspond to top most part of the tube i.e. an angle $90^{\circ}$ in Fig. 2(b). As shown in Fig.4 (a), the heat flux distribution on the absorber tube is symmetrical and only one half of the receiver can be considered i.e, $-90^{\circ} \leq \theta \leq 90^{\circ}$ shown in Fig. 2(b). Our results from Monte Carlo ray tracing were validated with available data from literature $[12,15,18]$. As shown in Fig. 4, for half the circumference of the receiver's absorber tube, our results for the local concentration ratio, LCR (the ratio of actual heat flux on the absorber tube to that incident on the reflector) show good agreement with available data. In this study, the concentrator was taken to be of perfect shape and perfect alignment.

\section{Numerical analysis}

The determination of temperature distribution in the receiver's absorber tube requires coupling the ray tracing results to a computational fluid dynamics tool. In this section, the necessary steps are presented and discussed. The flow inside the receiver's absorber tube is turbulent. In this investigation steady-state flow conditions are also assumed. 


\subsection{Governing equations}

The governing equations for steady-state and three-dimensional turbulent flow are the continuity, momentum and energy equations given by [34];

Continuity

$\frac{\partial\left(\rho u_{i}\right)}{\partial x_{i}}=0$

Momentum equation

$\frac{\partial}{\partial x_{j}}\left(\rho u_{i} u_{j}\right)=-\frac{\partial p}{\partial x_{i}}+\frac{\partial}{\partial x_{j}}\left[\mu_{e f f}\left(\frac{\partial u_{i}}{\partial x_{j}}+\frac{\partial u_{j}}{\partial x_{i}}\right)-\frac{2}{3} \mu_{e f f} \frac{\partial u_{i}}{\partial x_{i}} \delta_{i j}-\rho \overline{u_{i}^{\prime} u_{j}^{\prime}}\right]$

Energy equation

$$
\begin{aligned}
\frac{\partial}{\partial x_{j}}\left(\rho u_{j} c_{p} T\right)= & \frac{\partial}{\partial x_{j}}\left(\lambda \frac{\partial T}{\partial x_{j}}+\frac{\mu_{t}}{\sigma_{h, t}} \frac{\partial\left(c_{p} T\right)}{\partial x_{j}}\right)+u_{j} \frac{\partial p}{\partial x_{j}} \\
+ & {\left[\mu_{e f f}\left(\frac{\partial u_{i}}{\partial x_{j}}+\frac{\partial u_{j}}{\partial x_{i}}\right)-\frac{2}{3} \mu_{e f f} \frac{\partial u_{i}}{\partial x_{i}} \delta_{i j}-\rho \overline{u_{i}^{\prime} u_{j}^{\prime}}\right] \frac{\partial u_{i}}{\partial x_{j}} }
\end{aligned}
$$

Additional terms appearing in these equations represent the turbulence effects and the Reynolds stresses $-\rho \overline{u_{i}^{\prime} u_{j}^{\prime}} . \quad u_{i}, u_{j}$ are the time-averaged velocity components in the $i$ - and $j$ directions respectively and $T$ the time-averaged temperature. The effective viscosity is given by $\mu_{\text {eff }}=\mu+\mu_{t}$ and $\lambda$ is the fluid thermal conductivity. The most common approach for representation of Reynolds stresses is the Boussinesq approach, where the Reynolds stresses are related to the mean velocity gradients through [34]

$$
-\rho \overline{u_{i}^{\prime} u_{j}^{\prime}}=2 \mu_{t} S_{i j}-\frac{2}{3}\left(\rho k+\mu_{t} \frac{\partial u_{k}}{\partial x_{k}}\right) \delta_{i j}
$$

Such that

$$
-\rho \overline{u_{i}^{\prime} u_{j}^{\prime}}=\mu_{t}\left(\frac{\partial u_{i}}{\partial x_{j}}+\frac{\partial u_{j}}{\partial x_{i}}\right)-\frac{2}{3}\left(\rho k+\mu_{t} \frac{\partial u_{k}}{\partial x_{k}}\right) \delta_{i j}
$$

Where $k$ is the turbulent kinetic energy per unit mass given by

$$
k=\frac{1}{2}\left(\overline{u^{\prime 2}}+\overline{v^{\prime 2}}+\overline{w^{\prime 2}}\right)
$$

This approach has relatively lower computation cost requirements compared to the Reynolds stress transport model approach, which solves transport equations for each of the terms in the Reynolds stress tensor. In this study, the realisable $k-\varepsilon$ model was used for turbulence closure [34]. The additional equations required for the transport of turbulent kinetic energy and turbulent dissipation rates in the realisable $k-\varepsilon$ model are [34];

For $k$ 
$\frac{\partial}{\partial x_{j}}\left(\rho k u_{j}\right)=\frac{\partial}{\partial x_{j}}\left[\left(\mu+\frac{\mu_{t}}{\sigma_{k}}\right) \frac{\partial k}{\partial x_{j}}\right]+G_{k}-\rho \varepsilon$

And $\varepsilon$

$\frac{\partial}{\partial x_{j}}\left(\rho \varepsilon u_{j}\right)=\frac{\partial}{\partial x_{j}}\left[\left(\mu+\frac{\mu_{t}}{\sigma_{\varepsilon}}\right) \frac{\partial \varepsilon}{\partial x_{j}}\right]+\rho C_{1} S \varepsilon-\rho C_{2} \frac{\varepsilon^{2}}{k+\sqrt{v \varepsilon}}$

Where

$G_{k}$ represents production of turbulent kinetic energy and is modelled the same way for all the $k-\varepsilon$ models as

$G_{k}=-\rho \overline{u_{i}^{\prime} u_{j}^{\prime}} \frac{\partial u_{j}}{\partial x_{i}}$

Consistent with the Boussinesq's hypothesis

$G_{k}=\mu_{t} S^{2}$

The eddy viscosity is given by

$\mu_{t}=\rho C_{\mu} \frac{k^{2}}{\varepsilon}$

Detailed determination of $C_{\mu}$ is given in Ref. [34]. The model constants for the $k-\varepsilon$ realizable model are: $C_{1}=\max \left[0.43, \frac{\eta}{\eta+5}\right], \eta=S \frac{k}{\varepsilon}, S \equiv \sqrt{2 S_{i j} S_{i j}}, C_{2}=1.9, \sigma_{k}=1, \sigma_{\varepsilon}=1.2, S_{i j}$ represents the rate of linear deformation of a fluid element. In total, there are nine components in three dimensions, of which three are linear elongation deformation components and six are shearing and deformation components [34].

$$
S_{i j}=\frac{1}{2}\left(\frac{\partial u_{i}}{\partial x_{j}}+\frac{\partial u_{j}}{\partial x_{i}}\right)
$$

\subsection{Boundary conditions}

The boundary conditions used in this study were: (1) Non-uniform heat flux on the absorber tube's outer wall. The sample heat flux distribution used in this study is shown in Fig. 4(a) as determined using ray tracing in SolTrace [33] for rim angles of $80^{\circ}$ and $120^{\circ}$ and an aperture width of $6 \mathrm{~m}$ or concentration $\operatorname{ratio}\left(C_{R}\right)$ of 86 . A direct normal irradiance (DNI) of 1000 $\mathrm{W} / \mathrm{m}^{2}$ was assumed. (2) Velocity inlet and pressure outlet boundary conditions were used for the absorber tube's inlet and outlet respectively. (3) The inner absorber tube walls were considered no-slip and no-penetration. (4) For the inlet and outlet of the receiver's annulus space, symmetry boundary condition was used such that the normal gradients of all flow variables are zero. (5) For the outer wall of the glass cover, a mixed boundary condition is used to account for both radiation and convection heat transfer. Stefan Boltzmann's law with the sky as the external radiation enclosure gives radiation between the glass cover and the 
sky. Convection heat transfer from the glass cover to the surroundings was modelled by specifying a convection heat transfer coefficient and fluid temperature. The sky temperature is given by $T_{s k y}=0.0552 T_{a m b}{ }^{1.5}$ [35] while the wind heat transfer coefficient is given by $h_{w}=$ $V w^{0.58} d_{g o}{ }^{-0.42}$ [36]. A part from the validation cases where actual experimental conditions were used, the environmental conditions used in this study are shown in Table 1.

\subsection{Entropy generation}

The entropy generation was determined using the flow field variables obtained by solving the governing equations together with the boundary conditions. The entropy generation is determined from the heat transfer irreversibility $\left(S^{\prime \prime \prime}{ }_{g e n}\right)_{H}$ and fluid friction irreversibility $\left(S^{\prime \prime \prime}{ }_{\text {gen }}\right)_{F}$ according to the following equations [32].

$S_{g e n}^{\prime \prime \prime}=\left(S_{g e n}^{\prime \prime \prime}\right)_{F}+\left(S_{g e n}^{\prime \prime \prime}\right)_{H}$

The entropy generation due to the fluid friction irreversibility is given by

$\left(S_{g e n}^{\prime \prime \prime}\right)_{F}=S_{P R O D, V D}^{\prime \prime \prime}+S_{P R O D, T D}^{\prime \prime \prime}$

where

$S_{P R O D, V D}^{\prime \prime \prime}=\frac{\mu}{T}\left(\frac{\partial u_{i}}{\partial x_{j}}+\frac{\partial u_{j}}{\partial x_{i}}\right) \frac{\partial u_{i}}{\partial x_{j}}$

is the entropy production by direct dissipation and

$S_{P R O D, T D}^{\prime \prime \prime}=\frac{\rho \varepsilon}{T}$

is the entropy production by indirect (turbulent) dissipation.

The entropy generation due to the heat transfer irreversibility is given by

$\left(S_{g e n}^{\prime \prime \prime}\right)_{H}=S_{P R O D, T}^{\prime \prime \prime}+S_{P R O D, T G}^{\prime \prime \prime}$

where

$S_{P R O D, T}^{\prime \prime \prime}=\frac{\lambda}{T^{2}}(\nabla T)^{2}$

is the entropy production by heat transfer with mean temperatures and

$S_{P R O D, T G}^{\prime \prime \prime}=\frac{\alpha_{t}}{\alpha} \frac{\lambda}{T^{2}}(\nabla T)^{2}$

is the entropy production by heat transfer with fluctuating temperatures.

In Eq.(19), $\alpha$ and $\alpha_{t}$ are the thermal diffusivities. The flow field variables in these equations are timeaveraged quantities.

For a fluid occupying a volume $V$, total entropy generation rate is given by 


$$
S_{g e n}=\iiint_{V} S_{g e n}^{\prime \prime \prime} d V
$$

The relative contribution of each irreversibility to the total entropy generation rate is given by the Bejan number. The Bejan number $(B e)$ is defined as $B e=\left(S^{\prime \prime \prime}{ }_{g e n}\right)_{H} / S^{\prime \prime \prime}$ gen. The heat transfer irreversibility is dominant when $B e=1$ and fluid friction irreversibility is dominant when $B e=0$.

We have already shown that minimising the entropy generation due to heat transfer and fluid friction minimises the total entropy generation in the collector [25]. Therefore, in this study we consider only entropy generation due to heat transfer and fluid friction. The validation of the entropy generation model used in this paper was also done in our previous investigation [25] and will not be presented again.

\section{Numerical modelling procedure and validation}

\subsection{Solution procedure}

The numerical solution was implemented in a commercial software package ANSYS® 14.5. The geometry was built in ANSYS design modeler and the computational grid created in ANSYS meshing. The numerical solution is obtained in ANSYS FLUENT, which uses a finite volume method for solving the governing continuity, momentum, energy and $k-\varepsilon$ model equations. The SIMPLE algorithm put forward by Patankar and Spalding [37] was used for coupling the pressure and velocity. Second-order upwind schemes were employed for integrating the governing equations together with the boundary conditions over the computational domain. Given the need to capture a high resolution of gradients near the wall, the enhanced wall functions [34] were used with $y^{+} \approx 1$ used in all simulations. Where $y^{+}=$ $y \mu_{\tau} / v, v$ is the fluid's kinematic viscosity, $y$ is the distance from the wall, and $u_{\tau}$ is the friction velocity. To predict the near wall cell size, the distance y was calculated as $y=y^{+} \mu / \mu_{\tau} \rho$ Convergence was obtained with scaled residuals of mass, momentum, turbulent kinetic energy and turbulence dissipation rate less than $10^{-4}$ while the energy residuals were less than $10^{-7}$. Convergence was also monitored using the convergence history of volume-averaged entropy generation in the absorber tube. The solution was considered converged when the volume-averaged entropy generation remained constant for more than 200 successive iterations.

Mesh dependence studies for several refinements of the mesh were carried out with the volume integral entropy generation as a monitored quantity. The solution was considered mesh independent when $\left|\left(S_{\text {gen }}{ }^{i}-S_{\text {gen }}{ }^{i-1}\right) / S_{\text {gen }}{ }^{i-1}\right| \leq 0.01$. The indices $i$ and $i-1$ represent the values 
before and after refinement respectively. The sample mesh used in this study is shown in Fig. 5.

Syltherm 800 [38] was used as the absorber tube heat transfer fluid, its properties were entered as temperature dependent polynomials for specific heat capacity $\left(c_{p}\right)$, density $(\rho)$ and thermal conductivity $(\lambda)$ and piece-wise temperature dependent polynomial for viscosity $(\mu)$ as determined by curve fitting from the manufacturer's data sheets [38] and given by Eqs. (22-26). Sample thermal properties of Syltherm 800 at $T_{\text {inlet }}=400 \mathrm{~K}, 550 \mathrm{~K}$ and $650 \mathrm{~K}$ are shown in Table 2.0. The absorber tube material is stainless steel with a temperature dependent thermal conductivity [39] The emissivity of the absorber tube varies with temperature according to Eq.(21) [39]

$\xi=0.000327(T+273.15)-0.065971$

The thermal physical properties of Syltherm 800 [38] vary with temperature according to the following equations [38]

For $233.15 \leq T \leq 673.15 \mathrm{~K}$

$$
\begin{aligned}
& c_{p}=1.01787+1.70736 \times 10^{-3} \mathrm{~T}(\mathrm{~kJ} / \mathrm{kgK}) \\
& \rho=1.2691 \times 10^{3}-1.52115 T+1.79133 \times 10^{-3} \mathrm{~T}^{2}-1.67145 \times 10^{-6} \mathrm{~T}^{3}\left(\mathrm{~kg} / \mathrm{m}^{3}\right) \\
& \lambda=1.90134 \times 10^{-1}-1.88053 \times 10^{-4} \mathrm{~T}(\mathrm{~W} / \mathrm{mK})
\end{aligned}
$$

For $233.15 \leq T \leq 343 \mathrm{~K}$

$$
\begin{gathered}
\mu=5.14887 \times 10^{4}-9.61656 \times 10^{2} T+7.50207 T^{2}-3.12468 \times 10^{-2} T^{3}+7.32194 \times 10^{-5} T^{4} \\
-9.14636 \times 10^{-8} T^{5}+4.75624 \times 10^{-11} T^{6} \quad(\text { mPa.s })
\end{gathered}
$$

For $343 \leq T \leq 673.15 \mathrm{~K}$

$$
\begin{gathered}
\mu=9.88562 \times 10^{1}-7.30924 \times 10^{-1} T+2.21917 \times 10^{-3} T^{2}-3.42377 \times 10^{-6} T^{3} \\
+2.66836 \times 10^{-9} T^{4}-8.37194 \times 10^{-13} T^{5} \quad(\text { mPa.s })
\end{gathered}
$$

\subsection{Model validation}

Our receiver model was validated with experimental data from Dudley et al.[40]. Temperature gain and collector efficiency at various parabolic trough system operating conditions was compared with experimental data. In the validation of the receiver thermal model, a collector module with an aperture of $5 \mathrm{~m}$, a length of $7.8 \mathrm{~m}$, focal length of 1.49 and geometrical concentration ratio of 71 was used with similar environmental conditions as was 
used in the experiment [40]. As shown in Fig. 6, good agreement was obtained for both temperature gain and collector efficiency. At each inlet temperature shown in Figure 6, the experimental conditions are different as shown in Table D-1 presented in the test results of Dudley et al.[40].

\section{Results and discussions}

\subsection{Heat flux and temperature distribution}

The heat flux on the receiver's absorber tube circumference varies with the rim angle and the concentration ratio. Fig. 7(a) and 7(b) shows the variation of heat flux on the absorber tube's circumference at various rim angles for concentration ratios of 86 and 142 respectively. As shown in the figures, the heat flux profile varies greatly around the absorber tube's circumference depending mainly on the rim angle. At a given concentration ratio, low rim angles are shown to give high heat flux peaks and will give high absorber tube circumferential temperature gradients.

Figs. 8(a) and 8(b) show the variation of heat flux around the absorber tube's circumference at various concentration ratios for rim angles $40^{\circ}$ and $100^{\circ}$. As expected, as the concentration ratio increases, the heat flux on the absorber tube increases. At larger rim angles $\left(\varphi_{r}>60^{\circ}\right)$, the heat flux profile consists of a shadow effect area, increasing heat flux area, decreasing heat flux area and direct solar heat flux area [15]. From the figures, it can be noted that at very low rim angles $\left(\varphi_{r}<60^{\circ}\right)$, the shadow effect and heat flux increasing area do not exist and the peak heat flux increases. As the rim angles increase the shadow effect and heat flux increasing areas becomes more pronounced whereas the peak heat flux reduces.

At each concentration ratio, the peak heat flux increases as the rim angle reduces. This increase in peak heat flux increases the peak temperature and thus the finite temperature difference. Figs. 9(a) and 9(b) show the heat flux contours of the receiver's absorber tube at rim angles of $40^{\circ}$ and $120^{\circ}$ at a Reynolds number of $1.02 \times 10^{4}, T_{\text {inlet }}=400 \mathrm{~K}$ and a concentration ratio of 86 . For a given concentration ratio, Reynolds number and inlet temperature, it can be seen that the peak heat flux is higher at the lower rim angle $\left(\varphi_{r}=40^{\circ}\right)$ and lower at the higher rim angle $\left(\varphi_{r}=120^{\circ}\right)$. As shown in the figures, at low rim angles, only a small portion of the absorber tube receives concentrated solar heat flux. Figs. 10(a) and 10(b) show the temperature contours of the receiver's absorber tube at rim angles of $40^{\circ}$ and $120^{\circ}$ respectively at a Reynolds number of $1.02 \times 10^{4}, T_{\text {inlet }}=400 \mathrm{~K}$ and a concentration ratio of 86 . The temperature distribution around the absorber tube's circumference is similar 
to that of the heat flux at each respective rim angle shown in Figs. 9 (a) and 9(b). As expected, the temperature difference in the absorber tube at $40^{\circ}$ is higher than that at $120^{\circ}$. The absorber tube's temperature difference at these rim angles for the conditions considered is about $192{ }^{\circ} \mathrm{C}$ and $87.31^{\circ} \mathrm{C}$ respectively. The temperature difference reduces with increasing flow rates and increasing inlet temperatures due to improved heat transfer performance.

From the foregoing discussion, higher rim angles should be used to avoid such larger temperature differences especially at low Reynolds numbers. However, using larger rim angles increases the material requirements for the collector. Therefore, trade-off has to be made on how large the rim angle should be to avoid larger temperature difference while using as little material as possible. From Figs. 7 (a) and 7(b), it is seen that above a rim angle of $80^{\circ}$, the peak heat flux does not reduce significantly as the rim angle is increased further.

The effect of rim angle on the receiver's temperature distribution can also be illustrated by the circumferential temperature distribution in the receiver's absorber tube and annulus space. Figs. 11 (a \&b) show the circumferential temperature distribution in the receiver's absorber tube and receiver's annulus space respectively at a flow rate of $1.37 \times 10^{3} \mathrm{~m}^{3} / \mathrm{s}$, rim angle of $70^{\circ}$, concentration ratio of 71 and inlet temperature of $400 \mathrm{~K}$. Figs. 12 (a \& b) show the circumferential temperature distribution in the receiver's absorber tube and receiver's annulus space respectively at a flow rate of $1.37 \times 10^{3} \mathrm{~m}^{3} / \mathrm{s}$, rim angle of $40^{\circ}$, concentration ratio of 86 and inlet temperature of $600 \mathrm{~K}$. As shown in Figs. 11(b) and 12 (b), the circumferential temperature gradients also exist in the receiver's glass cover and this can cause glass breakage if the temperature gradients become extremely high especially at low Reynolds numbers, low rim angles and high concentration ratios.

\subsection{Entropy generation in the parabolic trough receiver}

As earlier discussed, the entropy generation is made of two parts: one due to heat transfer irreversibility across a finite temperature difference and the other due to fluid friction. Fig. 13 shows the variation of these parts and their relative contribution to the total entropy generation as the Reynolds number increases. As expected, at low Reynolds numbers, the heat transfer irreversibility is dominant and at high Reynolds numbers, the fluid friction is dominant. This kind of variation also yields a Reynolds number at which the total entropy generation rate is a minimum. This general trend can be obtained for other combinations of fluid temperature and concentration ratios at any given rim angle. 
The contribution of each irreversibility to the total entropy generation can be clearly shown by the Bejan number, $B e$. The Bejan number is the ratio of the entropy generation rate due to the heat transfer irreversibility to the total entropy generation rate. For values of the Bejan number close to 1 , the heat transfer irreversibility dominates and for values of the Bejan number close to 0 the fluid friction irreversibility dominates.

Fig, 14 shows the variation of the Bejan number with Reynolds number at different values of rim angles. At any rim angle, the Bejan number is shown to be close to 1 at lower values of Reynolds numbers, it then decreases as the Reynolds numbers increases. Be approaches 0 at very high Reynolds numbers. At a given Reynolds number, the Bejan number is shown to increase as the rim angle reduces. This is due to the high temperature peaks and the corresponding increase in the finite temperature difference as the rim angle reduces which increases the heat transfer irreversibility. As discussed in section 6.2, rim angles have a significant influence on the peak heat fluxes as well as peak temperatures in the receiver. Thus based on the graphs in Fig. 14, it can be seen that the heat transfer irreversibility increases as the rim angle reduces. The increase in the heat transfer irreversibility as rim angles reduce is more pronounced at higher Reynolds numbers.

From the entropy generation point of view, the higher the finite temperature difference, the higher the heat transfer irreversibility. Therefore, at the same flow rate or Reynolds number and concentration ratio the entropy generation is expected to reduce as the rim angle increases. Figs. 15 (a) and 15(b) shows the variation of entropy generation with Reynolds number at different rim angles for inlet temperatures of $400 \mathrm{~K}$ and $600 \mathrm{~K}$ respectively. As anticipated, the entropy generated increases as the rim angle reduces at each temperature considered. At the lowest Reynolds number in the figures the entropy generation reduces by about $35 \%$ and $72 \%$ at the respective temperatures as the rim angle increases from $40^{\circ}$ to $120^{\circ}$. Therefore, in addition to reducing the absorber tube's temperature difference, use of higher rim angles also ensures efficient utilisation of the available energy. From the figures, we also note that the entropy generation is smaller at higher temperatures than at lower temperatures due to improved heat transfer performance as fluid temperatures increase.

At higher temperatures, the heat transfer fluid becomes less viscous and less dense there by increasing the heat transfer rates. This reduces both the heat transfer and fluid irreversibilities. At the same flow rate, the Reynolds numbers also increase as the fluid temperature increases. The variation of entropy generation with temperature can be shown by considering a given flow rate. As shown in Figs. 16 (a) and 16 (b) at flow rates of $2.57 \times 10^{-3}$ 
$\mathrm{m}^{3} / \mathrm{s}$ and $2.22 \times 10^{-2} \mathrm{~m}^{3} / \mathrm{s}$ respectively, the entropy generation is generally shown to reduce as the temperature of the heat transfer fluid increases.

The variation of the entropy generation rate with concentration ratio was discussed in our earlier work [25]. For completeness, it is further briefly discussed here. Fig. 17 shows the variation of the entropy generation rate with Reynolds number at different concentration ratios. Same trend as previously obtained [25] is shown. Increasing concentration ratios increases the heat transfer irreversibility and thus the total entropy generation. It can also be seen that the optimal Reynolds number correspond to almost the same flow rate at the two temperatures. The variation of the Bejan number with Reynolds number at different concentration ratios is shown in Fig. 18. The Bejan number increases as the concentration ratio increases. This is mainly due to the increase in the heat transfer irreversibility as the concentration ratio increases as earlier discussed. Unlike, for rim angles, increasing the concentration ratios significantly increases the heat transfer irreversibility and therefore, the entropy generation rate. At the temperatures considered (400 K and $600 \mathrm{~K}$ ) in Fig. 17, the entropy generation rate increases by about $350 \%$ and $443 \%$ respectively as the concentration ratio increases from 57 to 143 at the lowest Reynolds number.

\section{Conclusion}

In this study, the second law of thermodynamics is used to analyse the entropy generation rates in a parabolic trough receiver at different rim angles, concentration ratios and fluid temperatures. A Monte Carlo ray trace method was used to obtain the heat flux distribution in the parabolic trough's receiver. Subsequently, the ray trace results were coupled with a finite volume method to determine the temperature distribution in the receiver's absorber tube and analyse the entropy generation in the parabolic trough receiver at different rim angles, concentration ratios and inlet temperatures.

From the study, it was found that, at low rim angle, the temperature differences in the receiver's absorber tube are significantly higher. As the rim angle increases, the absorber tube circumferential temperature differences reduce. The reduction in absorber tube's peak temperatures as the rim angles increase was shown to be small above rim angles of $80^{\circ}$. Regarding entropy generation, the entropy generation due to heat transfer and fluid flow in the receiver was shown to increase as the rim angle reduced. This is attributed to the higher finite temperature difference at low rim angles compared to that at high rim angles. Higher concentration ratios are also shown to give higher entropy generation rates for the same 
reasons. The Bejan number is shown to increase as the concentration ratio increases and as the rim angle reduces. The increase in the Bejan number is a further indication that the increase in entropy generation as the concentration ratio increases and as the rim angle reduces is mainly from the heat transfer irreversibility.

\section{Acknowledgement}

The funding received from NRF, TESP, and Stellenbosch University/University of Pretoria, SANERI/SANEDI, CSIR, EEDSM Hub and NAC is duly acknowledged and appreciated.

\section{REFERENCES}

[1] Philibert C, Frankl P. International Energy Agency, Technology roadmap: concentrating solar power. Paris, France: IEA/OECD, 2010.

[2] Richter C, Teske S, Short R. Concentrating solar power. Greenpeace/SolarPACES/ESTELA 2009; Global outlook 2009:1-86.

[3] Kalogirou SA. A detailed thermal model of a parabolic trough collector receiver. Energy 2012;48:298-306.

[4] Gong G, Huang X, Wang J, Hao M. An optimized model and test of the China's first high temperature parabolic trough solar receiver. Sol Energy 2010;84:2230-45.

[5] Burkholder F, Kutscher C. Heat loss testing of Schott's 2008 PTR70 parabolic trough receiver. NREL 2009; NREL/TP - 550-45633:1-58.

[6] Price H, Lüpfert E, Kearney D, Zarza E, Cohen G, Gee R et al. Advances in parabolic trough solar power technology. Sol Energy Eng 2002; 124:109-25.

[7] Lüpfert E, Pfänder M, Schiricke B, Eck M. Determination of temperature distribution on parabolic trough receivers. 13th International symposium on concentrating solar power and chemical energy technologies 2006; A1-S6.

[8] Tyagi SK, Wang S, Singhal MK, Kaushik SC, Park SR. Exergy analysis and parametric study of concentrating type solar collectors. Int J Therm Sci 2007;46:1304-10.

[9] Price H, Forristall R, Wendelin T, Lewandowski A, Moss T, Gummo C. Field Survey of Parabolic Trough Receiver Thermal Performance. ASME Conf Proc 2006; ISEC200699167.

[10] Barra OA, Franceschi L. The parabolic trough plants using black body receivers: Experimental and theoretical analyses. Sol Energy 1982;28:163-71.

[11] Lüpfert E, Riffelmann K, Price H, Burkholder F, Moss T. Experimental analysis of overall thermal properties of parabolic trough receivers. Sol Energy Eng 2008;130:021007. 
[12] Yang B, Zhao J, Xu T, Zhu Q. Calculation of the concentrated flux density distribution in parabolic trough solar concentrators by Monte Carlo ray-trace method. Photonics and Optoelectronic (SOPO) 2010:1-4.

[13] SunShot Initiative-High-concentration low cost parabolic trough system for baseload CSP, available at: http://www1.eere.energy.gov/solar/sunshot/csp_baseload_skyfuel.html . U S Department of Energy; last accessed [ 22.02.2013].

[14] Price H, Kearney D. Parabolic-trough technology roadmap:A pathway for sustained commercial development and deployment of parabolic trough technology. NREL January, 1999; NREL/TP-550-24748:1-35.

[15] He Y, Xiao J, Cheng Z, Tao Y. A MCRT and FVM coupled simulation method for energy conversion process in parabolic trough solar collector. Renew Energ 2011;36:976-85.

[16] Lei D, Li Q, Wang Z, Li J, Li J. An experimental study of thermal characterization of parabolic trough receivers. Energy Conversion and Management 2013;69:107-15.

[17] Muñoz J, Abánades A. Analysis of internal helically finned tubes for parabolic trough design by CFD tools. Appl Energy 2011;88:4139-49.

[18] Jeter SM. Analytical determination of the optical performance of practical parabolic trough collectors from design data. Sol Energy 1987;39:11-21.

[19] Thomas A, Thomas SA. Design data for the computation of thermal loss in the receiver of a parabolic trough concentrator. Energ Convers Manage 1994;35:555-68.

[20] Bejan A. A study of entropy generation in fundamental convective heat transfer. J Heat Transfer 1979;101:718-25.

[21] Bejan A. Entropy generation minimization: the method of thermodynamic optimization of finite-size systems and finite-time processes. Boca Raton, Fla.: CRC Press, 1996.

[22] Le Roux WG, Bello-Ochende T, Meyer JP. Operating conditions of an open and direct solar thermal Brayton cycle with optimised cavity receiver and recuperator. Energy 2011;36:6027-36.

[23] le Roux WG, Bello-Ochende T, Meyer JP. Thermodynamic optimisation of the integrated design of a small-scale solar thermal Brayton cycle. Int $\mathrm{J}$ Energy Res 2012;36:1088-104.

[24] Bejan A. Entropy Generation through Heat and Fluid Flow. , 1982.

[25] Mwesigye A, Bello-Ochende T, Meyer JP. Numerical investigation of entropy generation in a parabolic trough receiver at different concentration ratios. Energy 2013;53:114-27.

[26] Ko TH, Cheng CS. Numerical investigation on developing laminar forced convection and entropy generation in a wavy channel. Int Commun Heat Mass 2007;34:924-33. 
[27] Khan WA, Yovanovich MM, Culham JR. Optimization of microchannel heat sinks using entropy generation minimization method. IEEE Transaction on components and packaging technologies 2009;32:243-51.

[28] Baloyi J, Bello-Ochende T, Meyer JP. Thermodynamic optimisation and computational analysis of irreversibilities in a small-scale wood-fired circulating fluidised bed adiabatic combustor. Energy 2014;70:653-663.

[29] Ghazikhani M, Hatami M, Ganji DD, Gorji-Bandpy M, Behravan A, Shahi G. Exergy recovery from the exhaust cooling in a DI diesel engine for BSFC reduction purposes. Energy 2014;65:44-51.

[30] Ghazikhani M, Hatami M, Safari B. The effect of alcoholic fuel additives on exergy parameters and emissions in a two stroke gasoline engine. Arabian Journal for Science and Engineering 2014;39:2117-25.

[31] Kalogirou SA. Solar thermal collectors and applications. Prog Energ Combust 2004;30:231-95.

[32] Herwig H, Kock F. Direct and indirect methods of calculating entropy generation rates in turbulent convective heat transfer problems. Heat and Mass Transfer 2007;43:207-15.

[33] NREL. SolTrace optical modelling software. SolTrace 2012;2012.7.9.

[34] ANSYS $®$ Academic research, release 14.5, ANSYS FLUENT, theory guide, ANSYS, Inc.

[35] García-Valladares O, Velázquez N. Numerical simulation of parabolic trough solar collector: Improvement using counter flow concentric circular heat exchangers. Int J Heat Mass Trans 2009;52:597-609.

[36] Mullick SC, Nanda SK. An improved technique for computing the heat loss factor of a tubular absorber. Solar Energy 1989;42:1-7.

[37] Patankar SV, Spalding DB. A calculation procedure for heat, mass and momentum transfer in three-dimensional parabolic flows. Int J Heat Mass Transfer 1972;15:1787-806.

[38] SYLTHERM 800 heat transfer fluid:product techinical data. http://www.dow.com/heattrans/products/synthetic/syltherm.htm. Last accessed [12.06.2013].

[39] Forristall R. Heat transfer analysis and modeling of a parabolic trough solar receiver implemented in Engineering Equation solver. NREL October 2003;NREL/TP-550-34169:1145 .

[40] Dudley EV, Kolb JG, Mahoney AR, Mancini T, R., Sloan M, Kearney D. Test results: SEGS LS-2 solar collector. Sandia National Laboratory 1994;SAND94-1884. 


\section{List of Figures}

Fig. 1. 3-D model of a parabolic trough collector

Fig. 2. Parabolic trough receiver (a) Longitudinal view (b) Cross-section view

Fig. 3. Ray trace output at an aperture width of $10 \mathrm{~m}$ (a) $\varphi_{r}=80^{\circ}$ (b) $\varphi_{r}=40^{\circ}$

Fig. 4. (a) Sample heat flux distribution for rim angles of $80^{\circ}$ and $120^{\circ}$ and an aperture width of $6 \mathrm{~m}$. (b) Validation of ray tracing results

Fig. 5. Sample mesh (a) cross-section view (b). Longitudinal view (symmetry plane)

Fig. 6. Validation of parabolic trough thermal model

Fig. 7. Variation of heat flux around the absorber tube wall at various rim angles (a) $C_{R}=86$ (b) $C_{R}=143$

Fig. 8. Variation of heat flux around the absorber tube wall at various concentration ratios (a) $\varphi_{r}=40^{\circ}$ (b) $\varphi_{r}=100^{\circ}$

Fig. 9. Contours of absorber tube heat flux at $R e=1.02 \times 10^{4}, T_{\text {inlet }}=400 \mathrm{~K}$ and $C_{R}=86$ (a) $\varphi_{r}=40^{\circ}$ (b) $\varphi_{r}=120^{\circ}$

Fig. 10. Contours of absorber tube temperature at $R e=1.02 \times 10^{4}, T_{\text {inlet }}=400 \mathrm{~K}$ and $C_{R}=86$ (a) $\varphi_{r}=40^{\circ}$ (b) $\varphi_{r}=120^{\circ}$

Fig. 11. Temperature contours at a flow rate of $1.37 \times 10^{-3} \mathrm{~m}^{3} / \mathrm{s}, T_{\text {inlet }}=400 \mathrm{~K}, \varphi_{r}=70^{\circ}$ and $C_{R}=71$ (a) Inside the absorber tube (b) Receiver's annulus space

Fig. 12. Temperature contours at a flow rate of $1.37 \times 10^{-3} \mathrm{~m}^{3} / \mathrm{s}, T_{\text {inlet }}=600 \mathrm{~K}, \varphi_{r}=40^{\circ}$ and $C_{R}=86$ (a) Inside the absorber tube (b) Receiver's annulus space

Fig. 13. Variation of entropy generation due to fluid friction, heat transfer and total entropy with Reynolds number at an inlet temperature of $400 \mathrm{~K}, C_{R}=86$ and $\varphi_{r}=80^{\circ}$

Fig. 14. Variation of Bejan with Reynolds number at different values of rim angles for $C_{R}=$ 86 (a) $T_{\text {inlet }}=400 \mathrm{~K}$ (b) $T_{\text {inlet }}=600 \mathrm{~K}$

Fig. 15. Variation of entropy generation with Reynolds numbers at different values of rim angles for $C_{R}=86$. (a) $T_{\text {inlet }}=400 \mathrm{~K}$ (b) $T_{\text {inlet }}=600 \mathrm{~K}$

Fig. 16. Variation of entropy generation with inlet temperature at different values of rim angles for $C_{R}=86$ (a) $\dot{V}=2.57 \times 10^{-3} \mathrm{~m}^{3} / \mathrm{s}$ (b) $\dot{V}=2.22 \times 10^{-2} \mathrm{~m}^{3} / \mathrm{s}$

Fig. 17. Variation of entropy generation with Reynolds number at different concentration ratios for $\varphi_{r}=80^{\circ}$ (a) $T_{\text {inlet }}=400 \mathrm{~K}$ (b) $T_{\text {inlet }}=600 \mathrm{~K}$ 
Fig. 18. Variation of Bejan number with Reynolds number at different concentration ratios for $T_{\text {inlet }}=500 \mathrm{~K}$ and $\varphi_{r}=80^{\circ}$ 


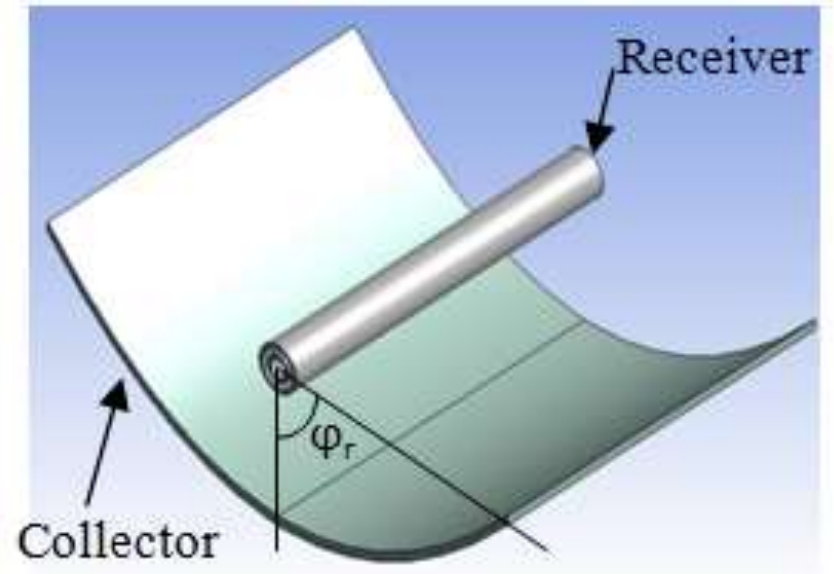

Fig. 1. 

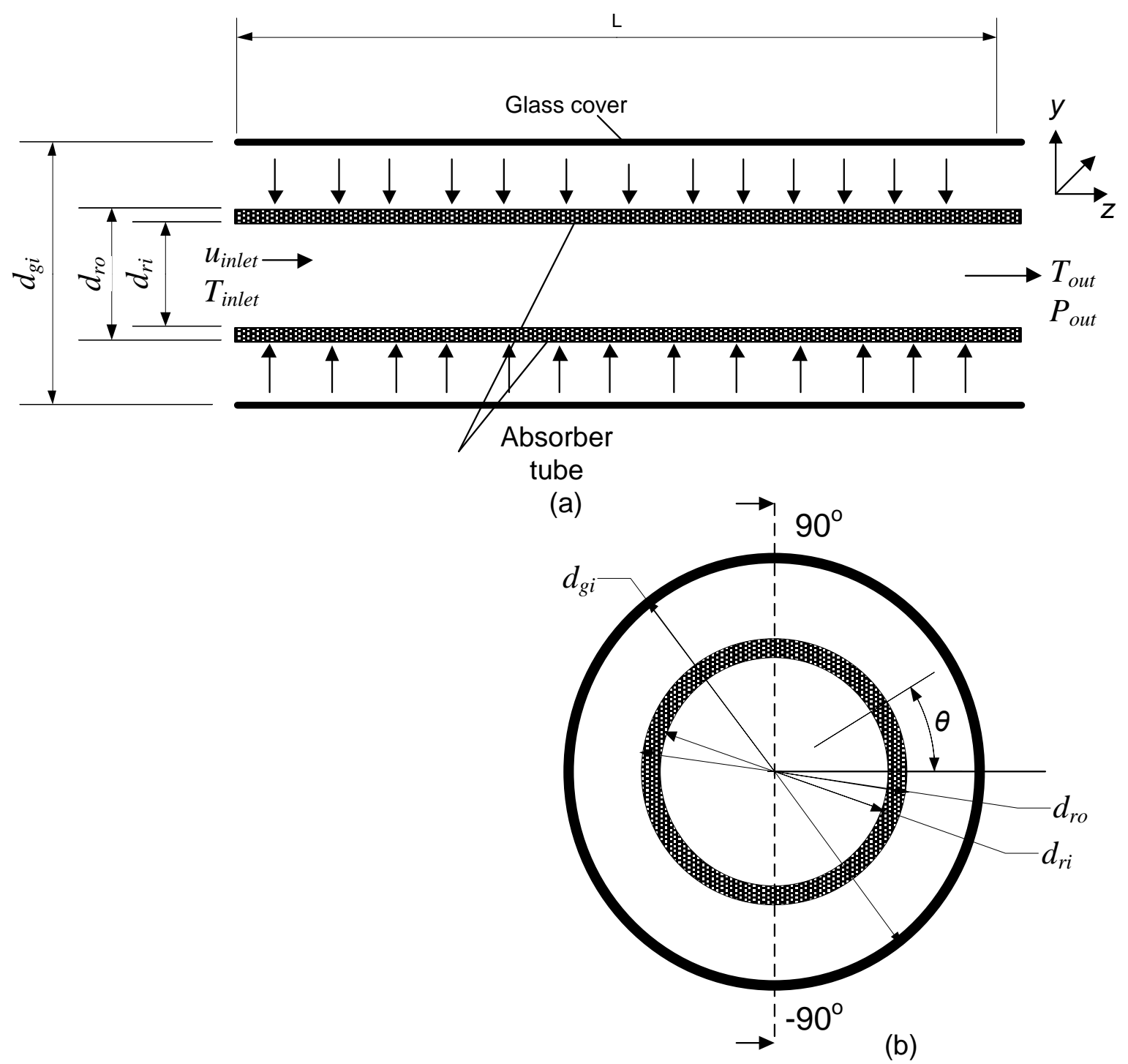

Fig. 2. 


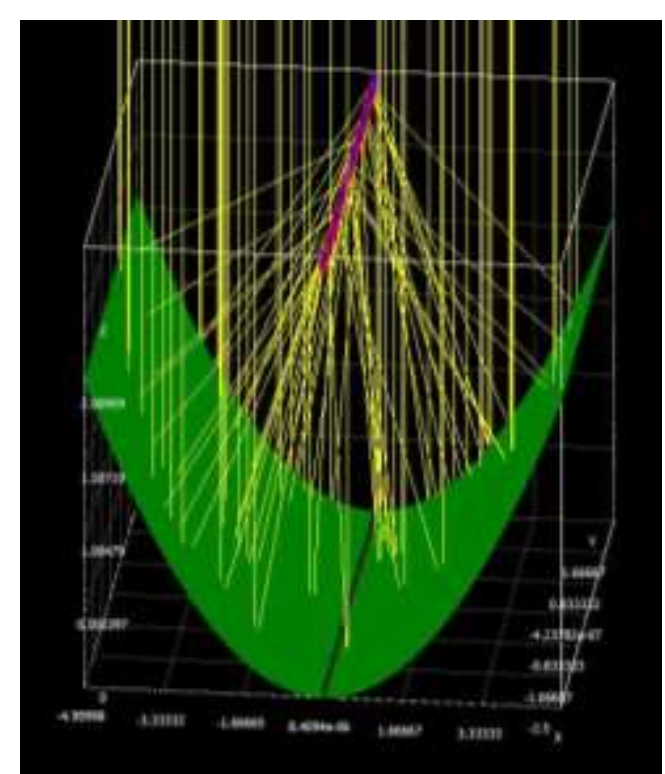

(a)

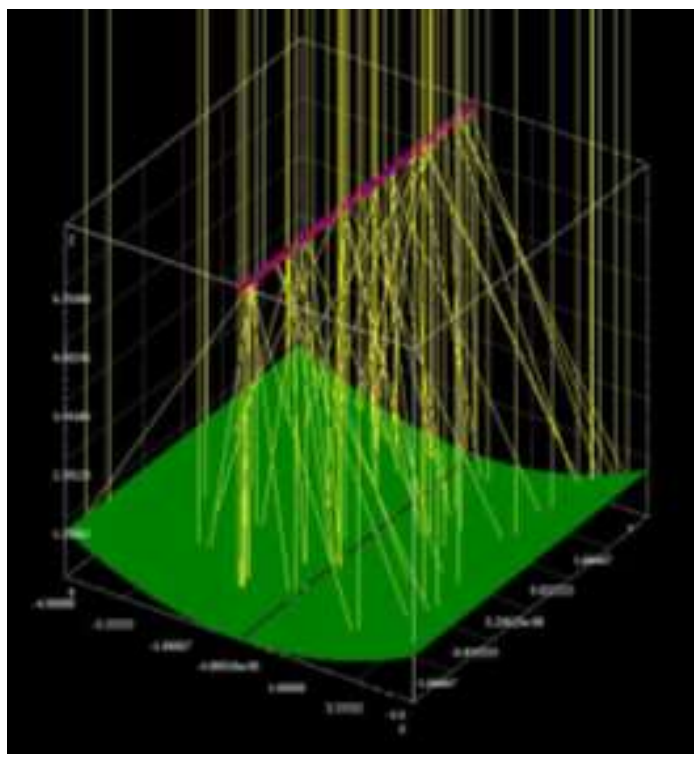

(b)

Fig. 3. 

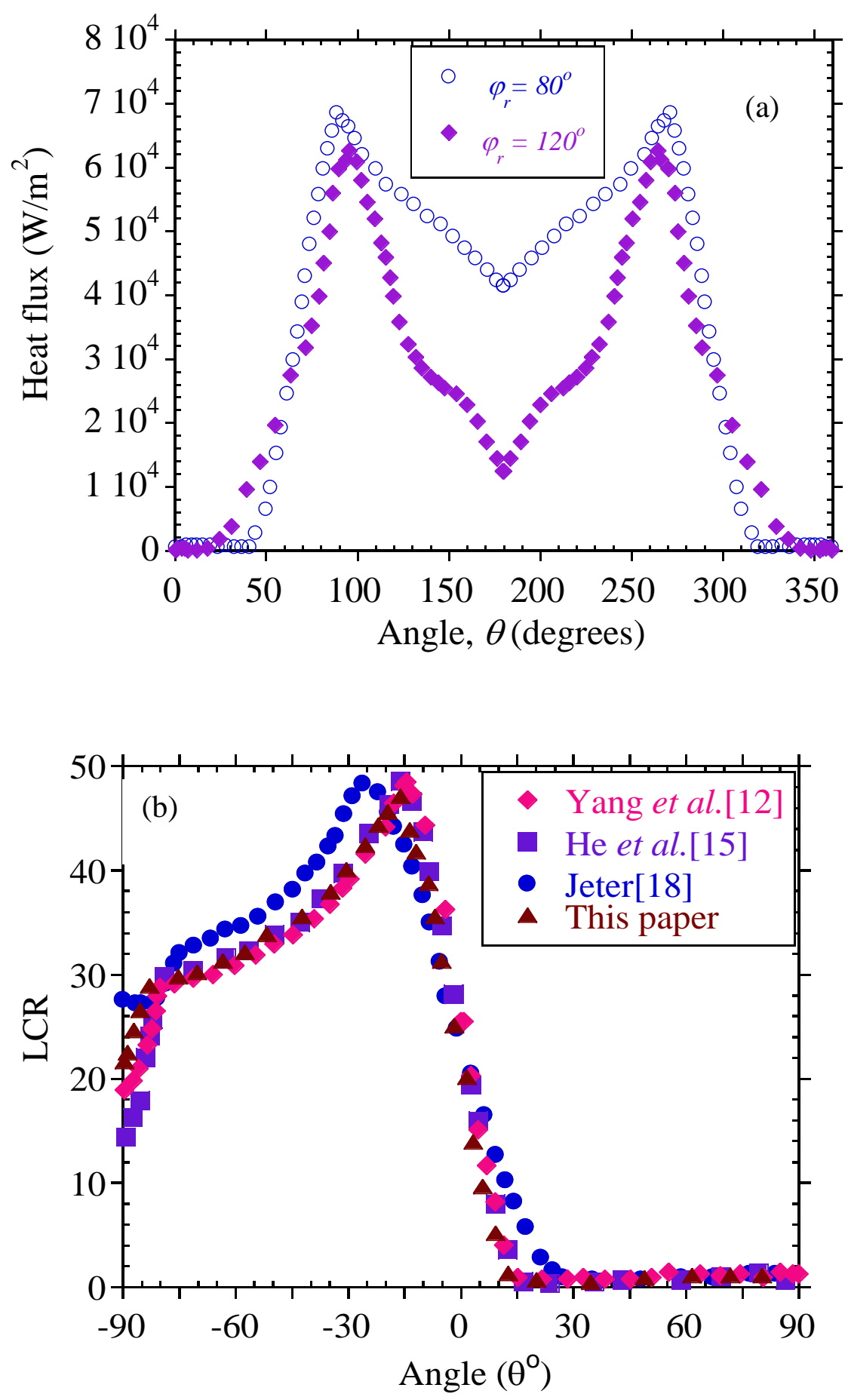

Fig. 4. 

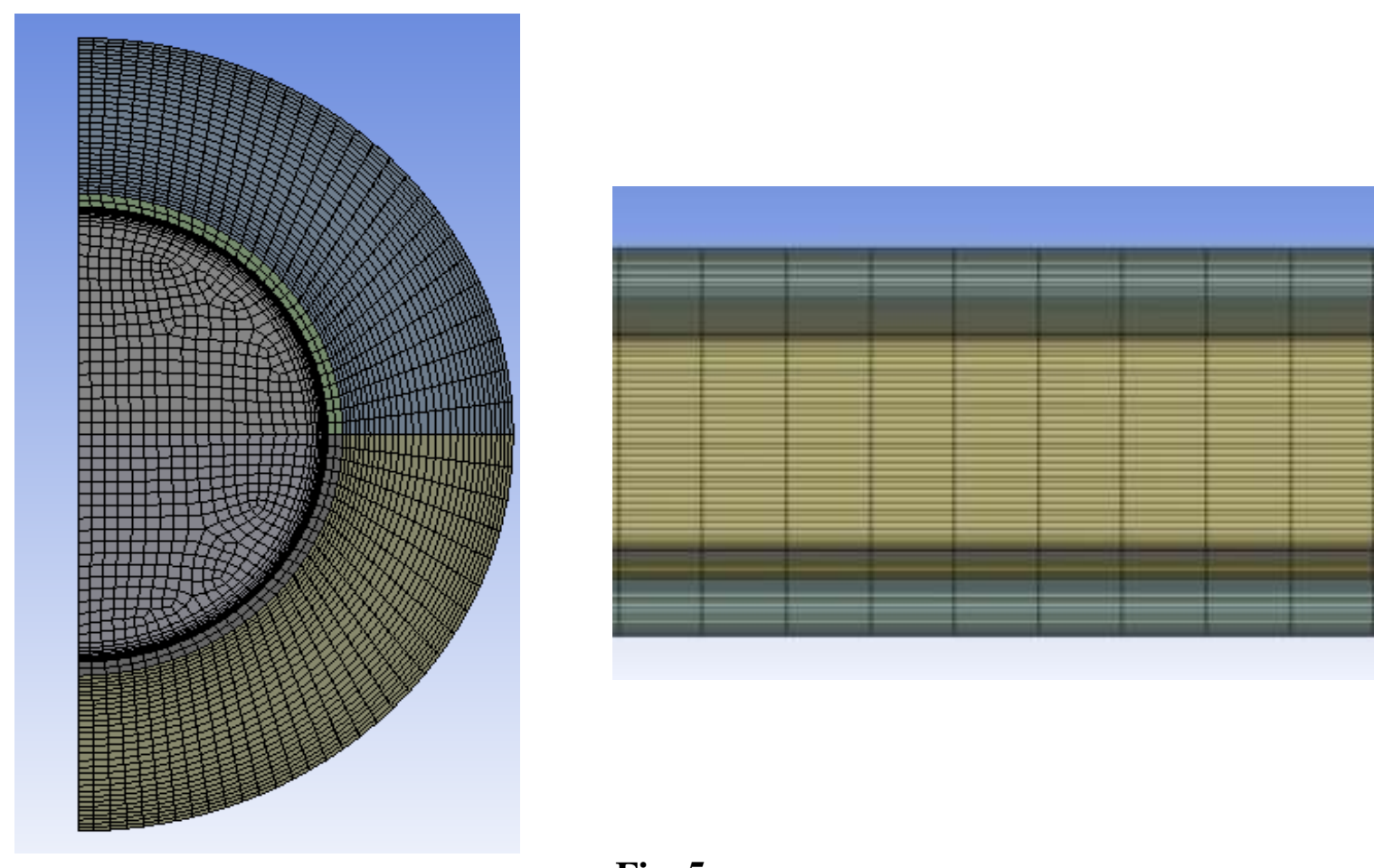

Fig. 5. 


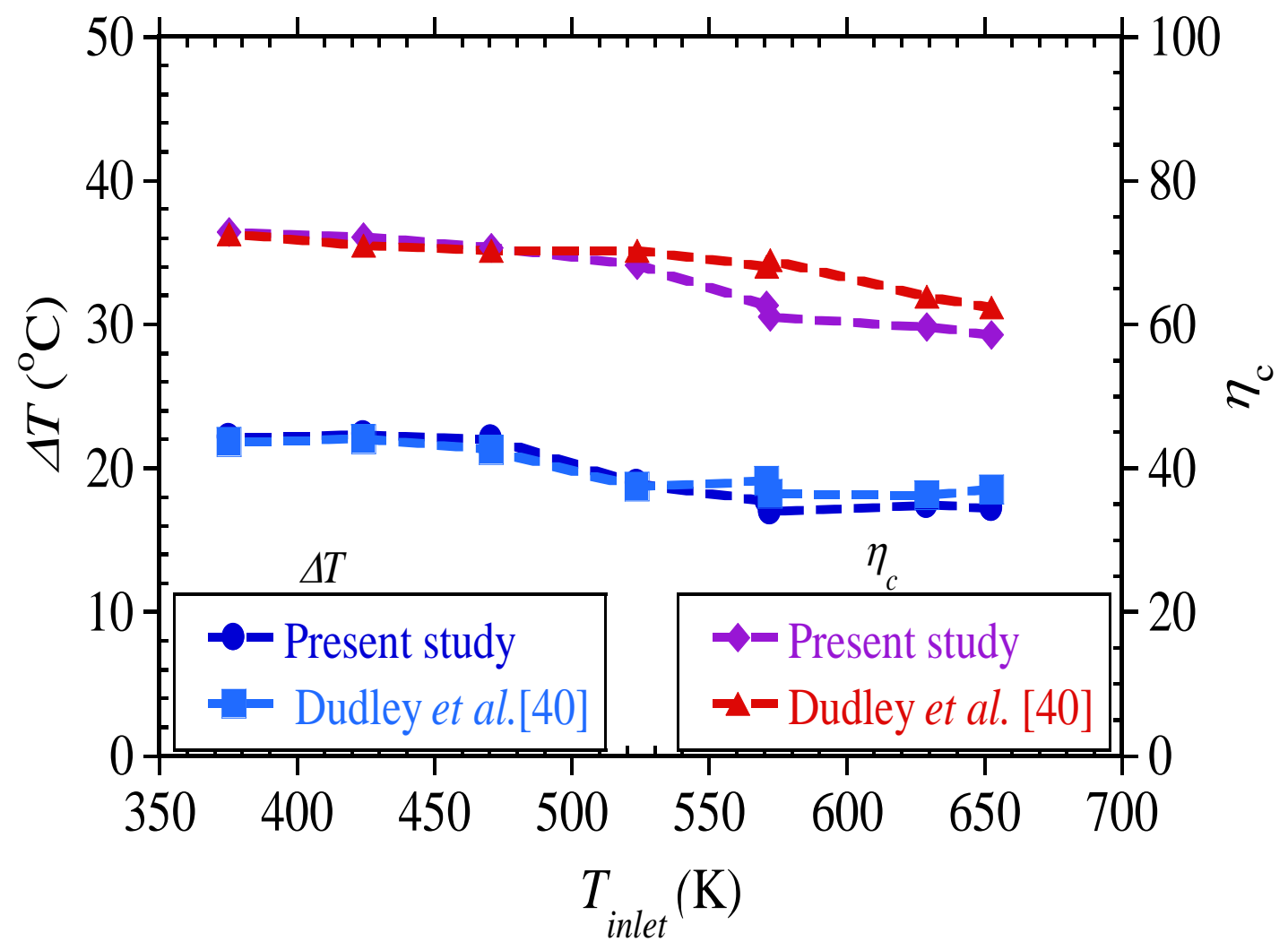

Fig. 6. 

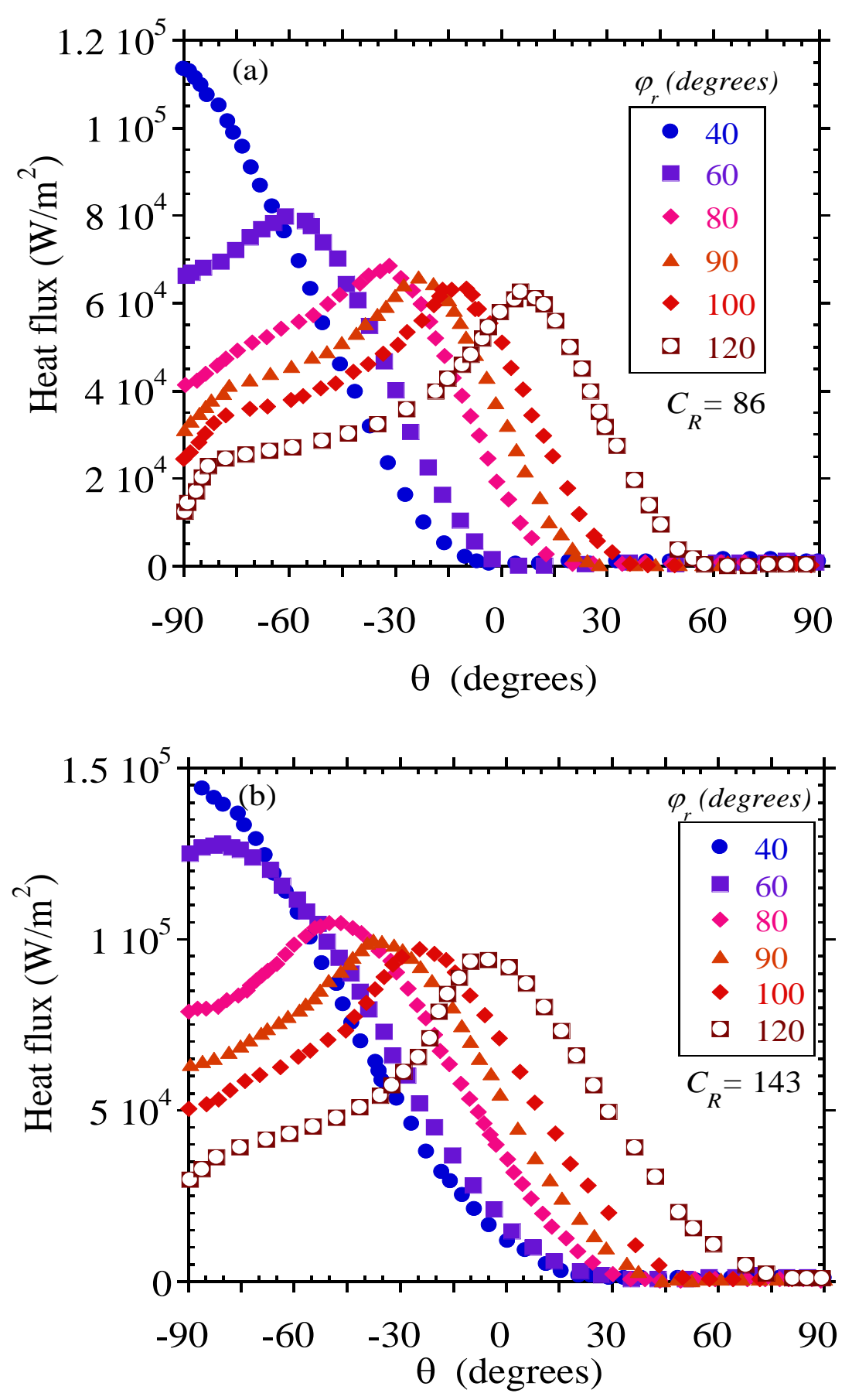

Fig. 7. 

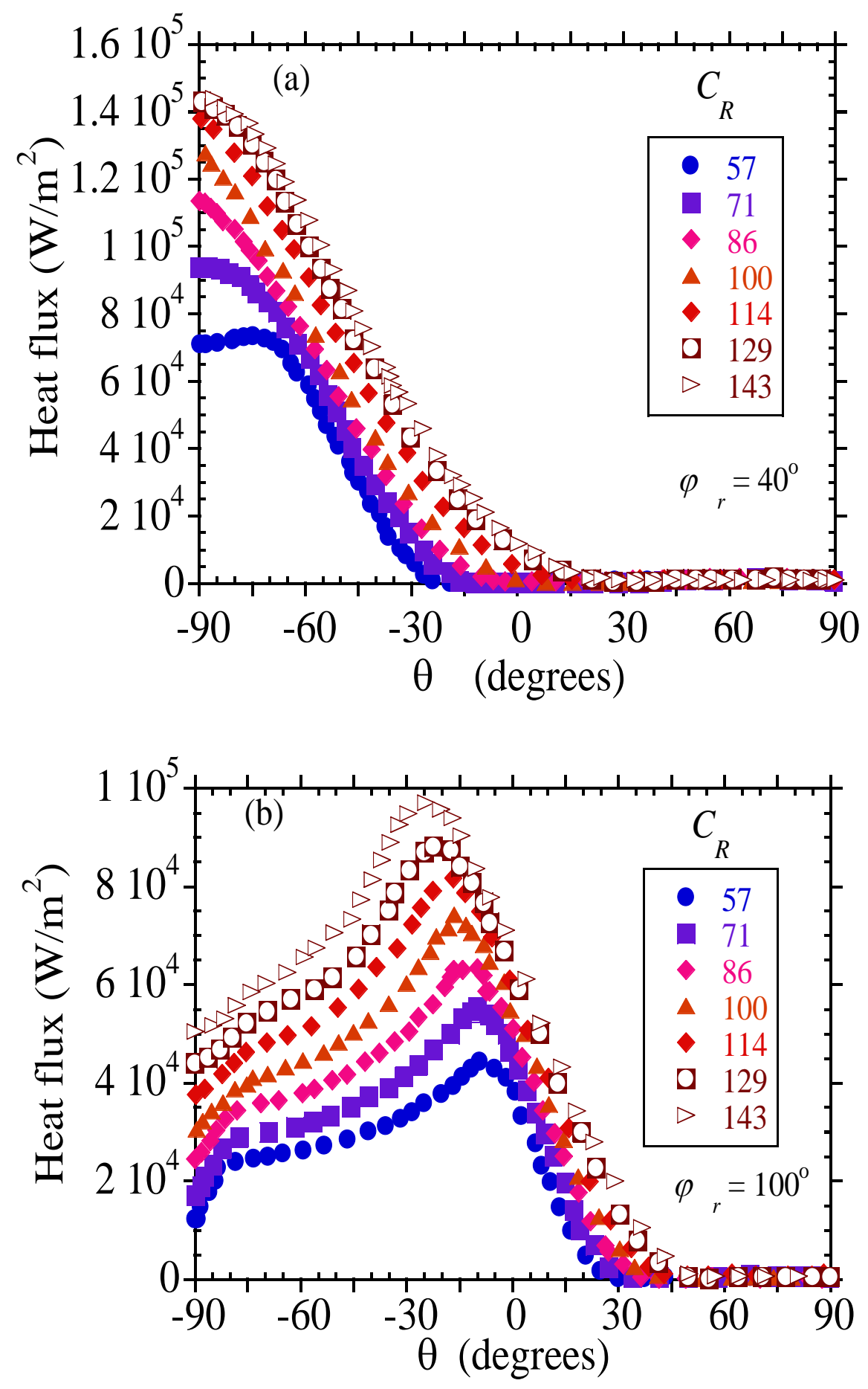

Fig. 8. 

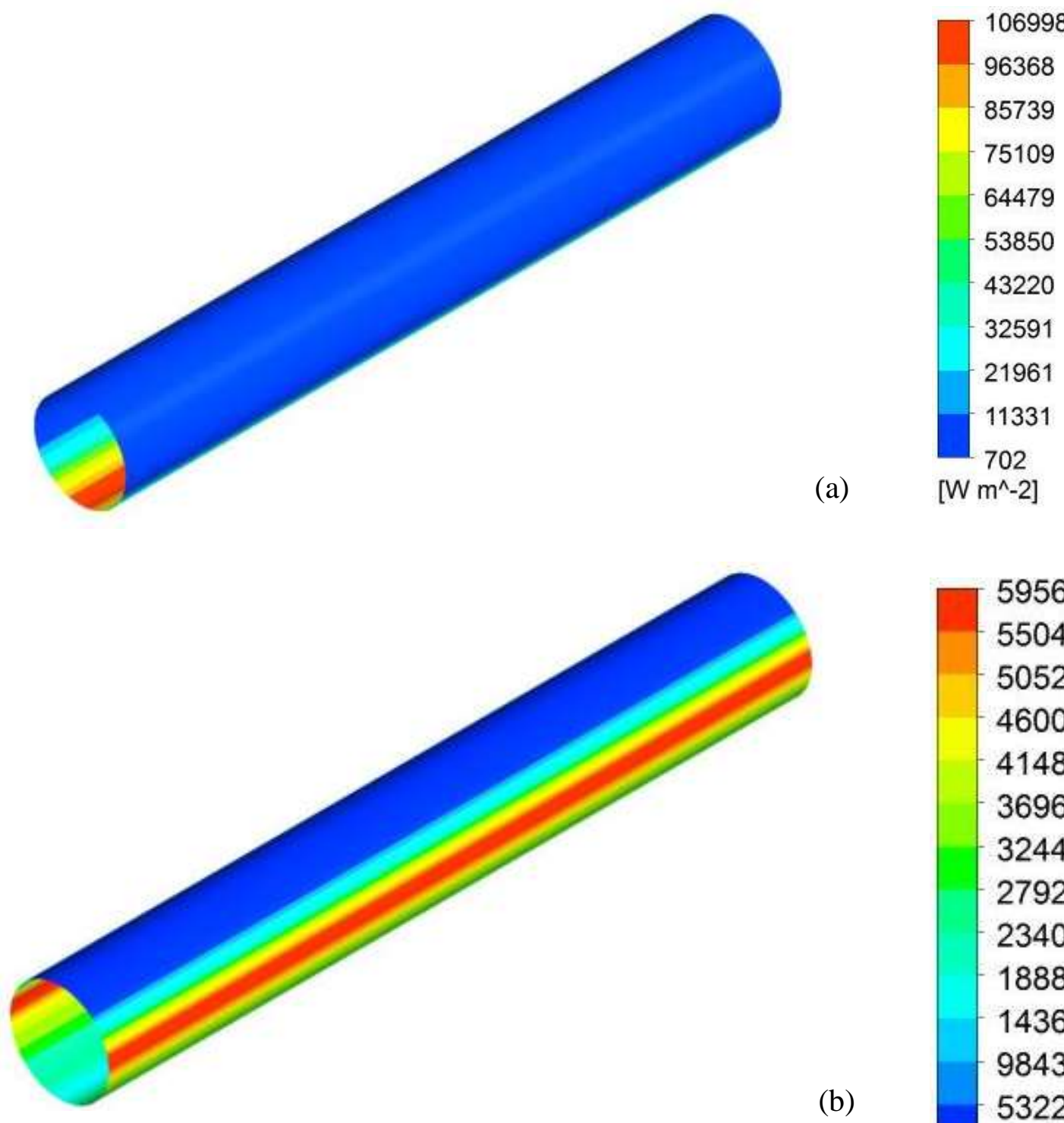

(a) $\quad\left[\mathrm{W} \mathrm{m}^{\wedge}-2\right]$

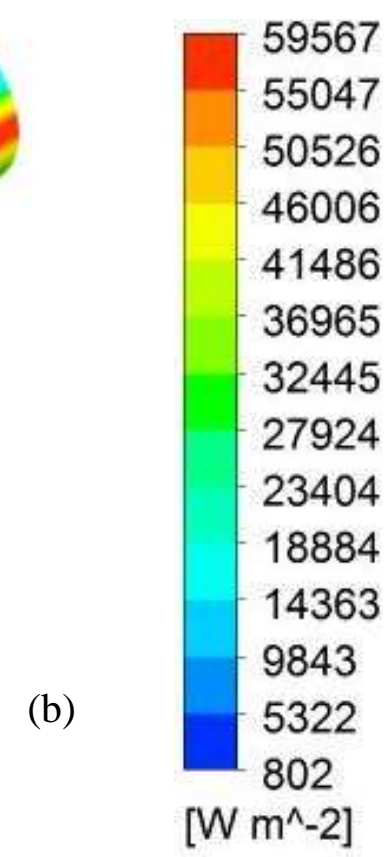

Fig. 9. 


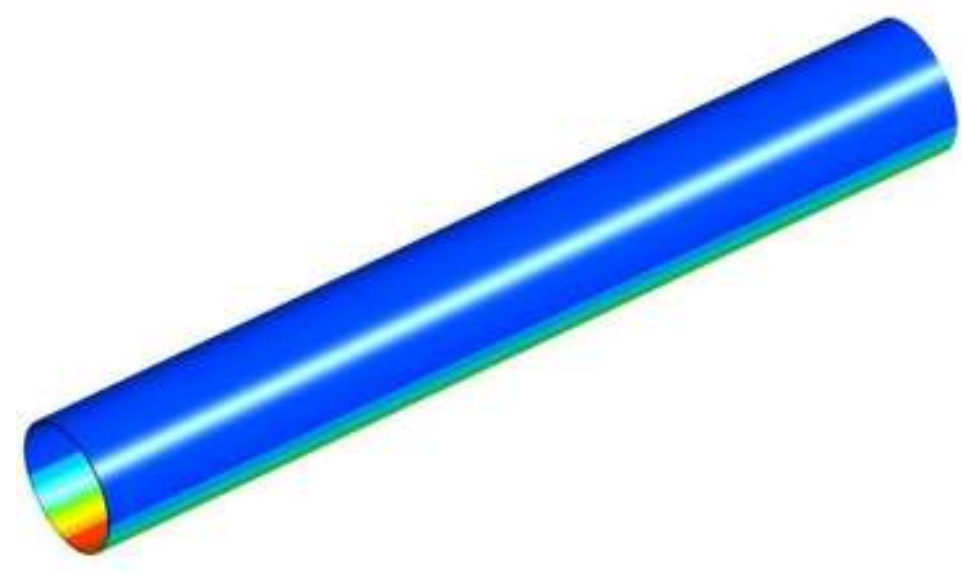

(a)

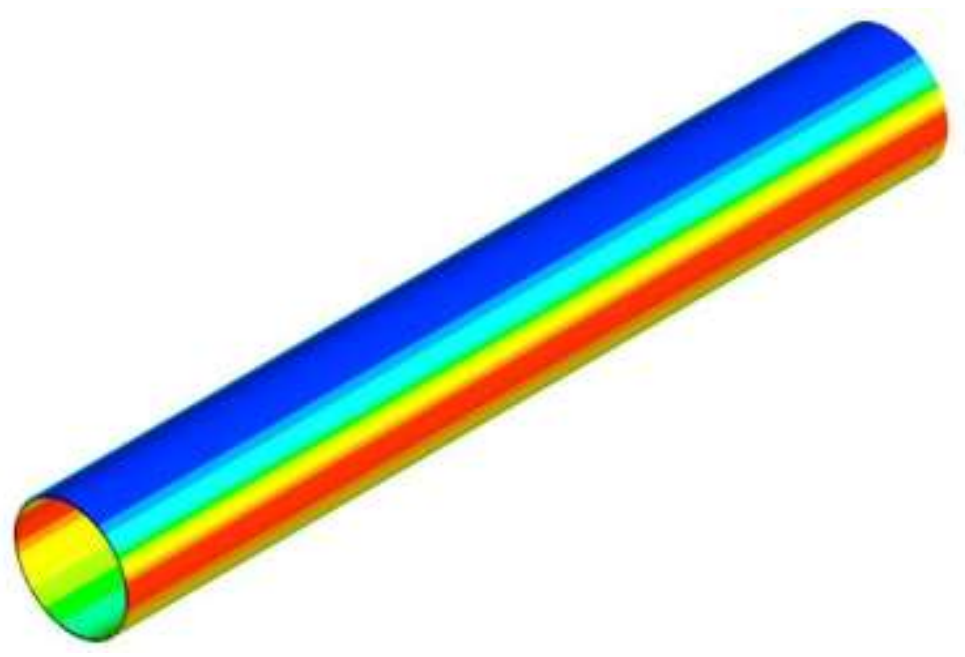

(b)

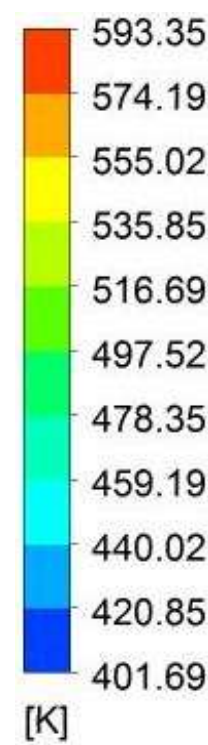

490.73

484.02

477.30

470.58

463.87

457.15

450.43

443.72

437.00

430.29

423.57

416.85

410.14

403.42

[K]

Fig. 10. 


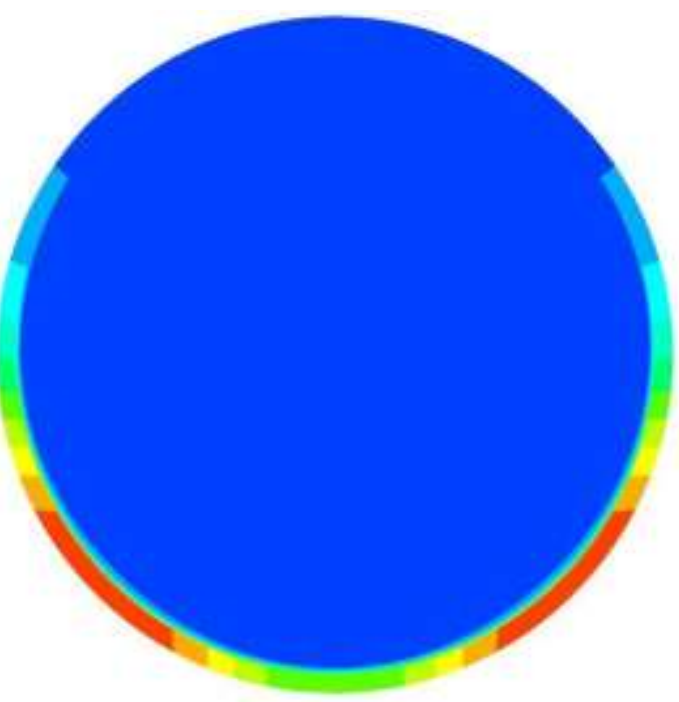

(a)
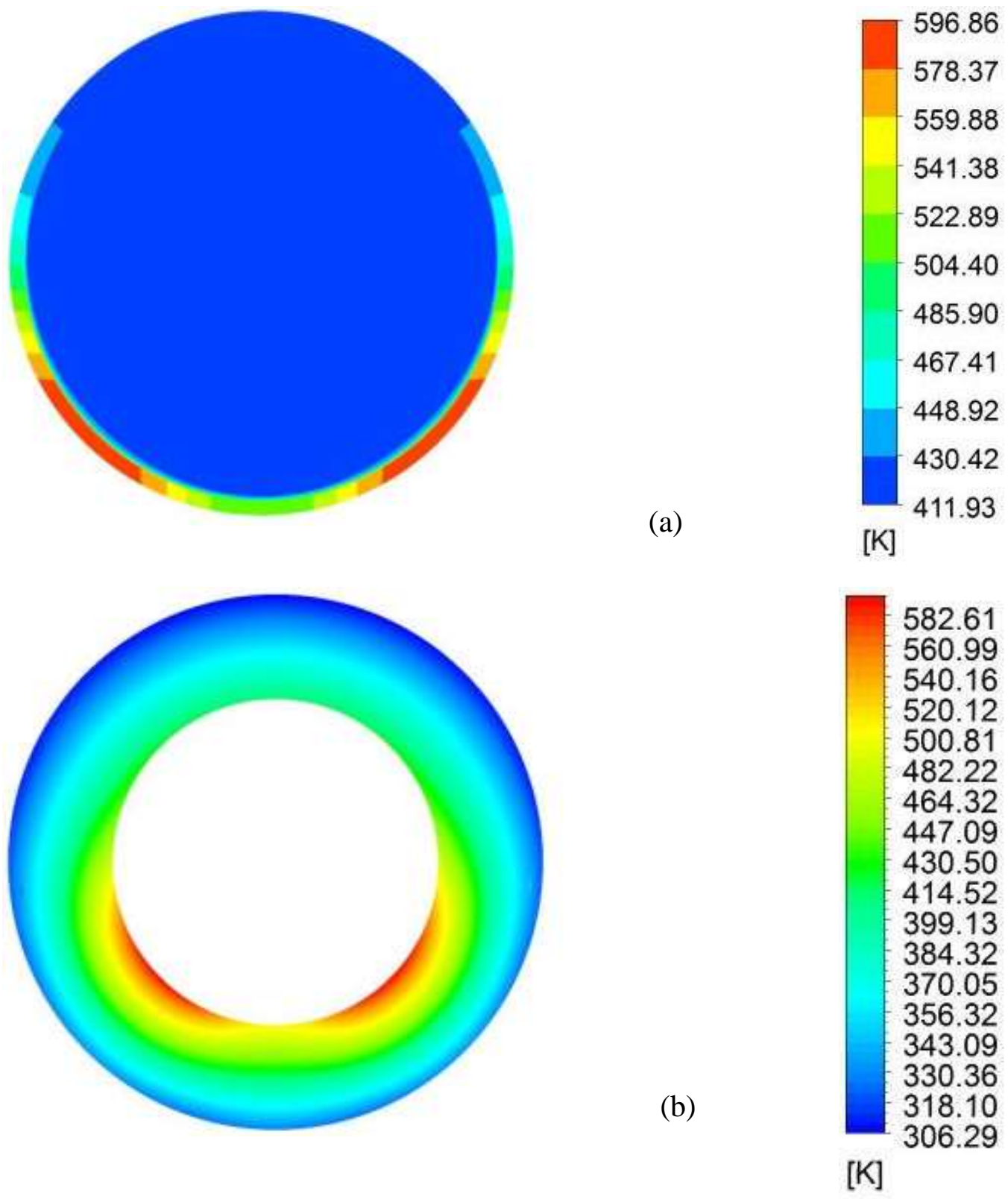

Fig. 11. 


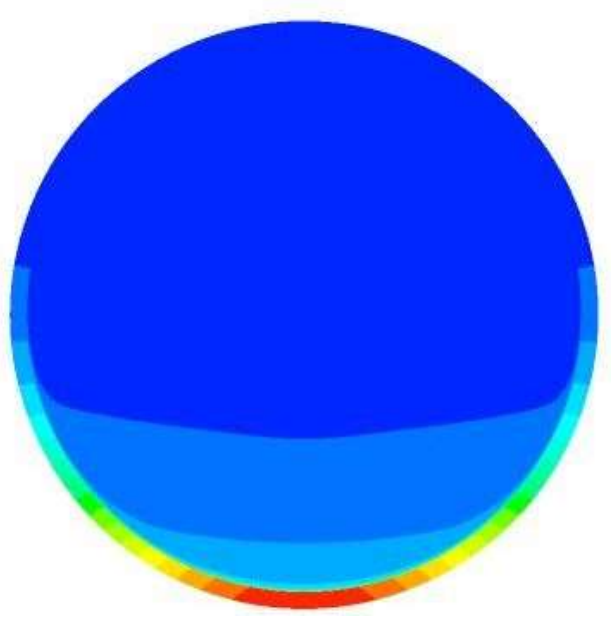

(a)
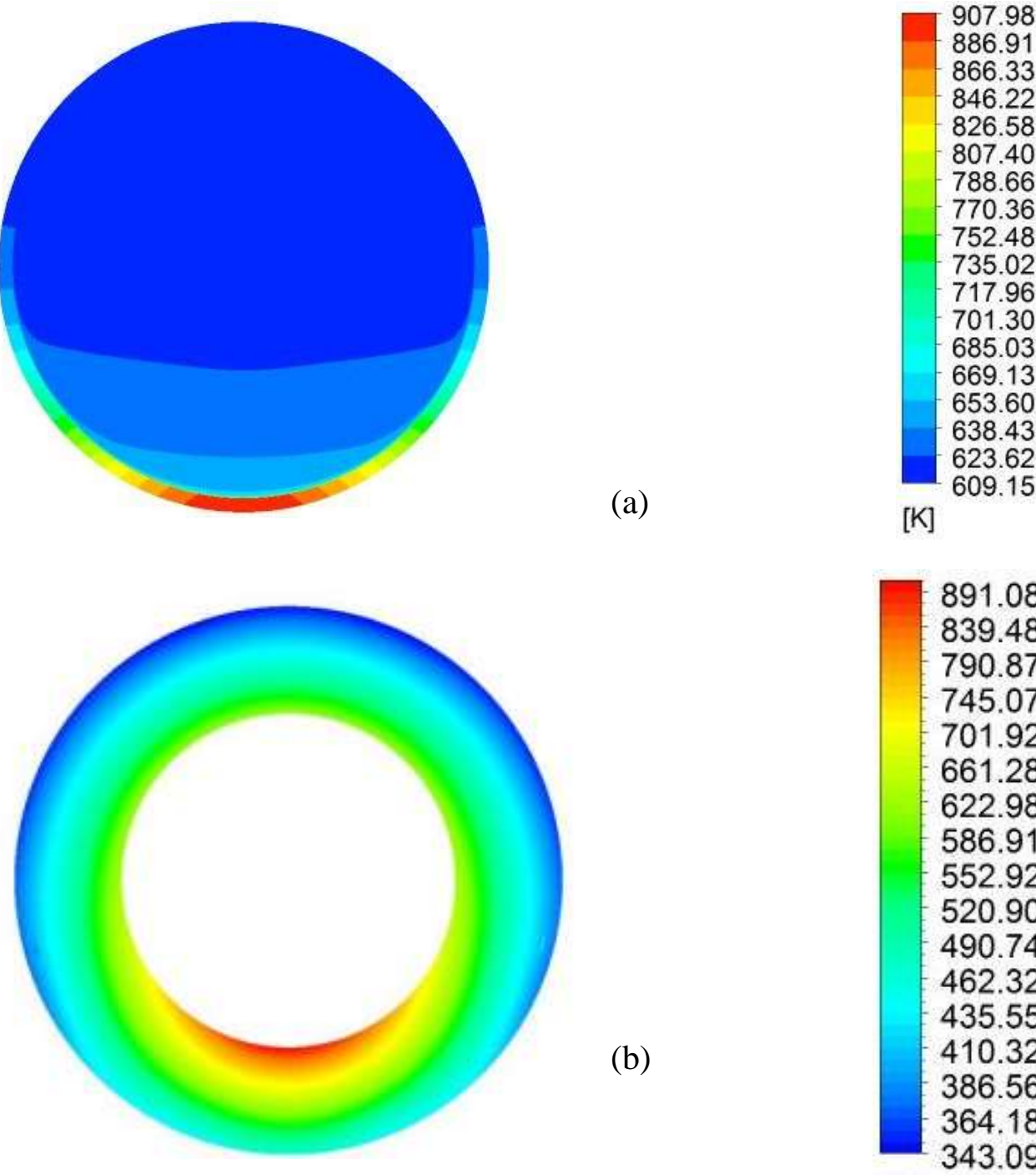

(b)

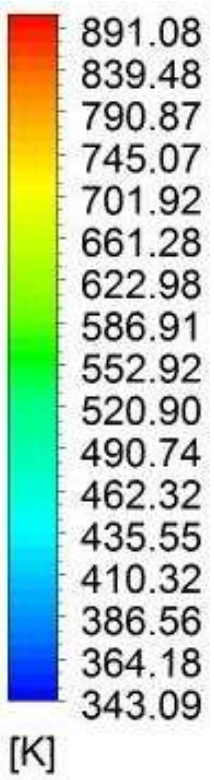

Fig. 12. 


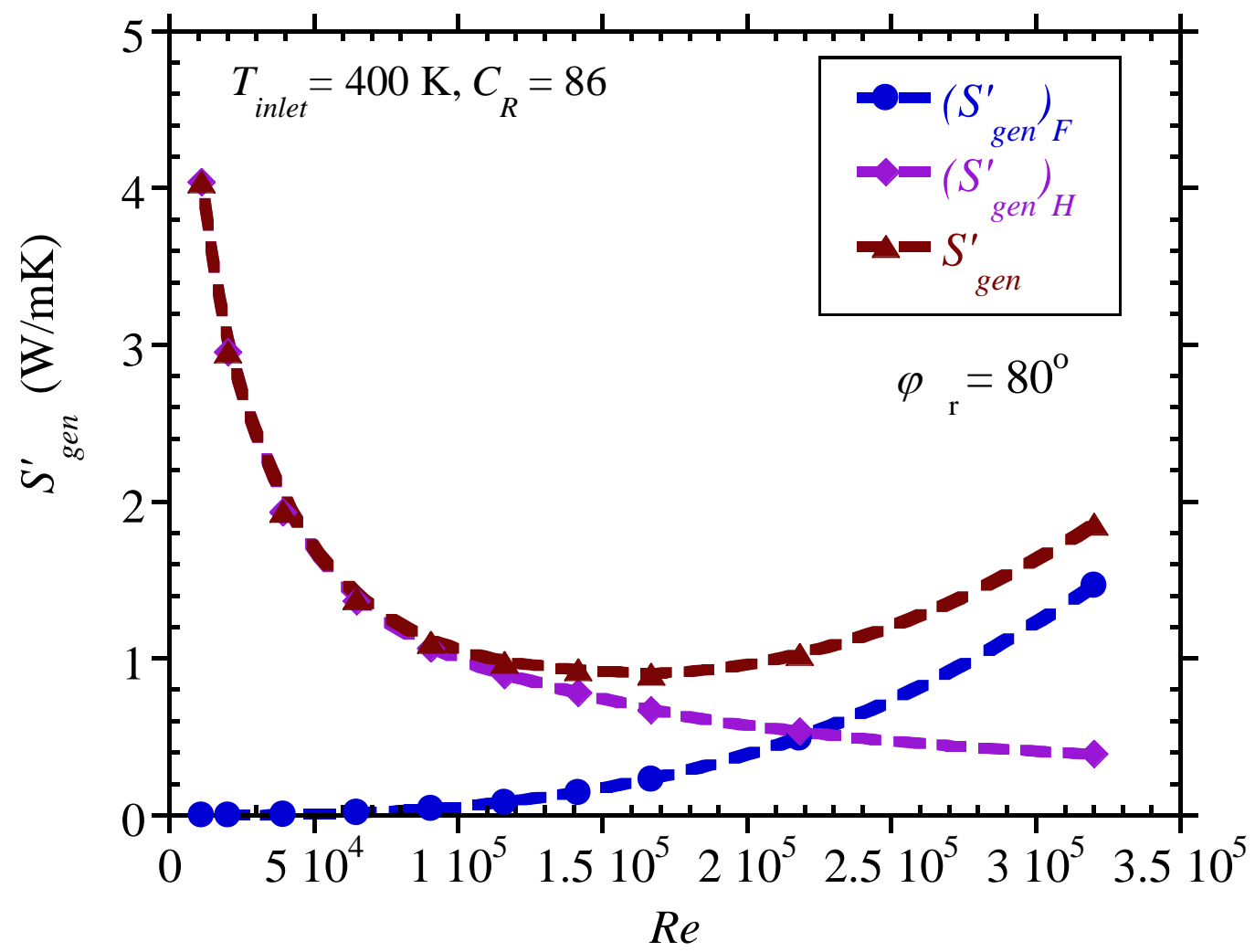

Fig. 13. 

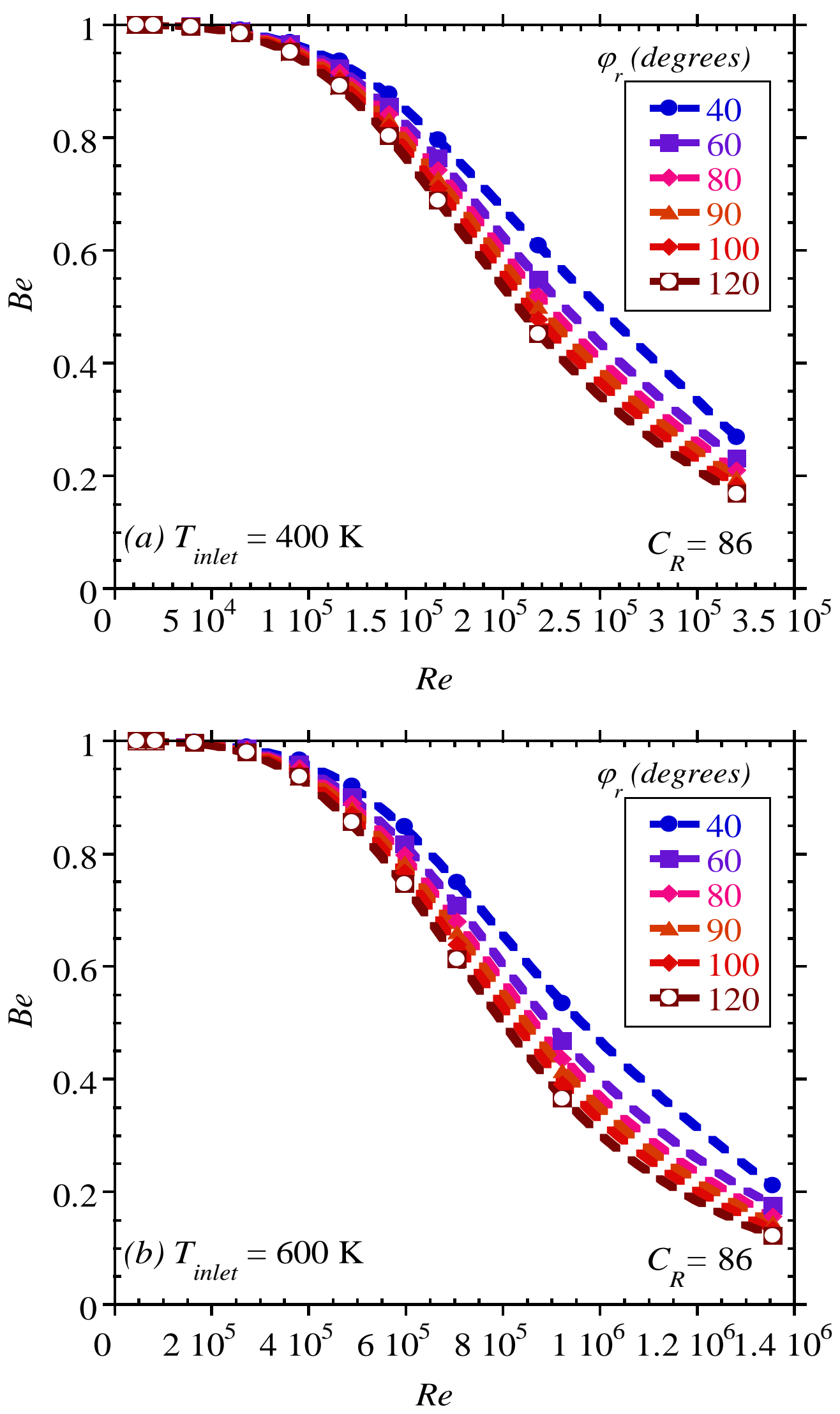

Fig. 14. 

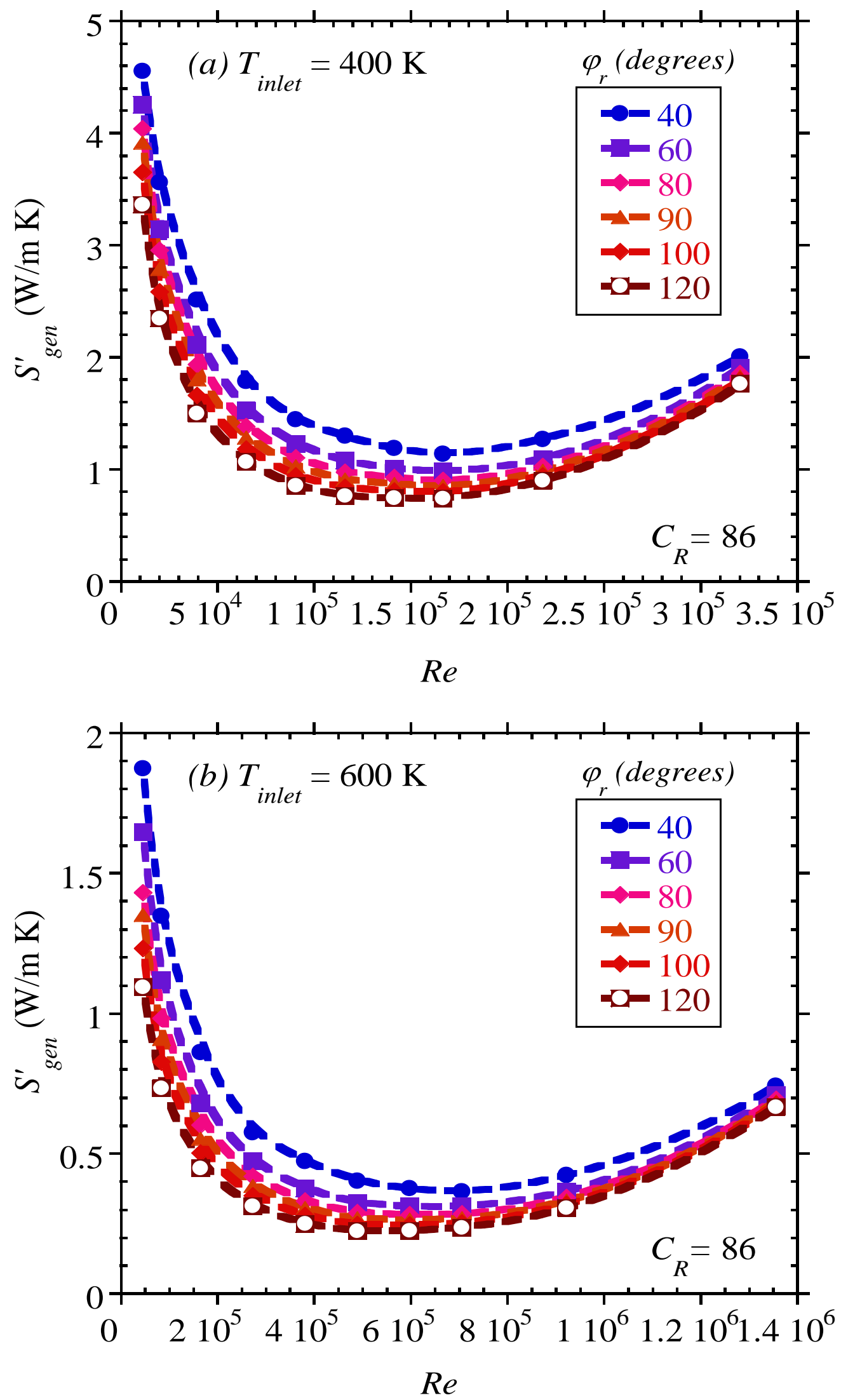

Fig. 15. 

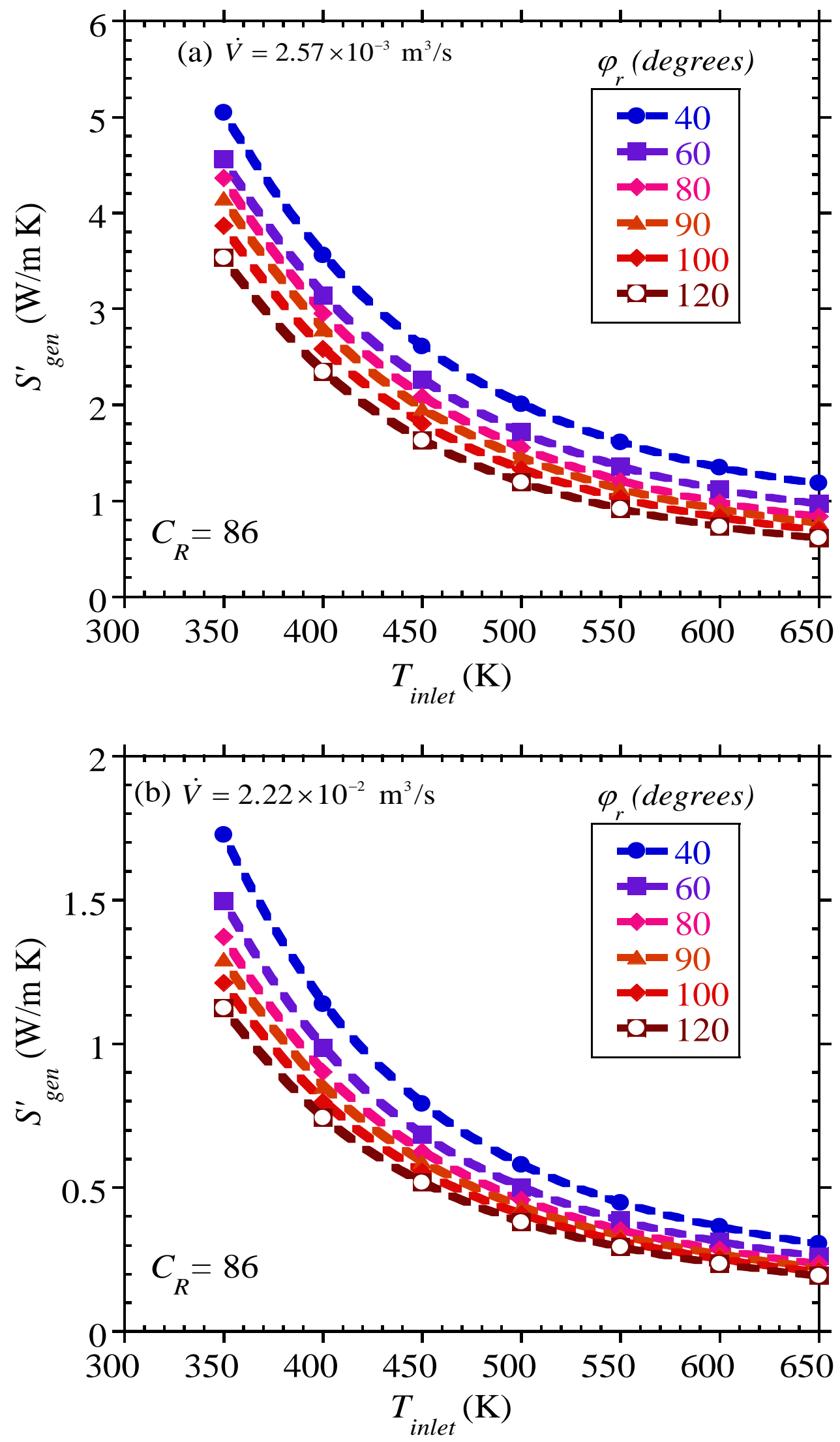

Fig. 16. 

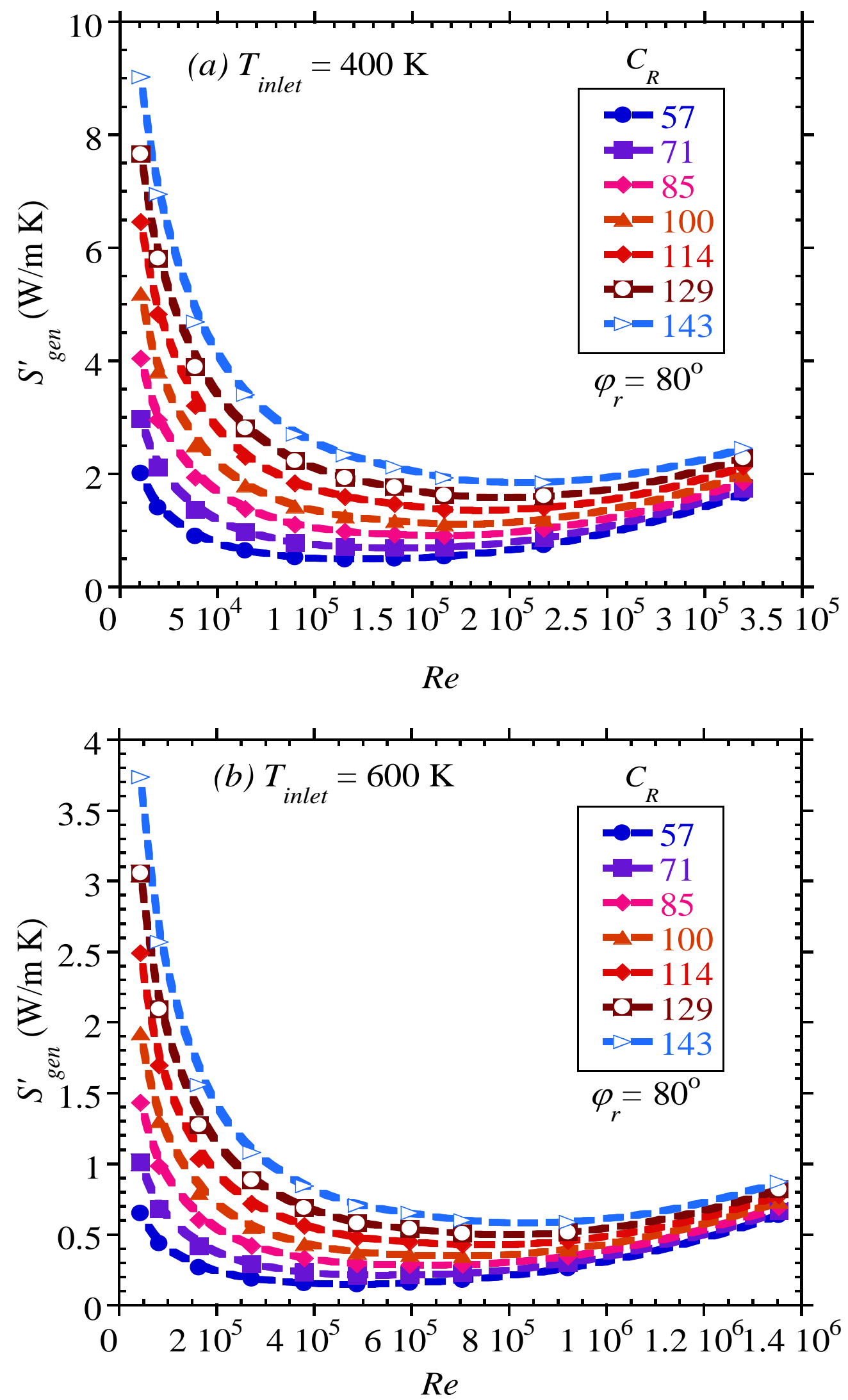

Fig. 17. 


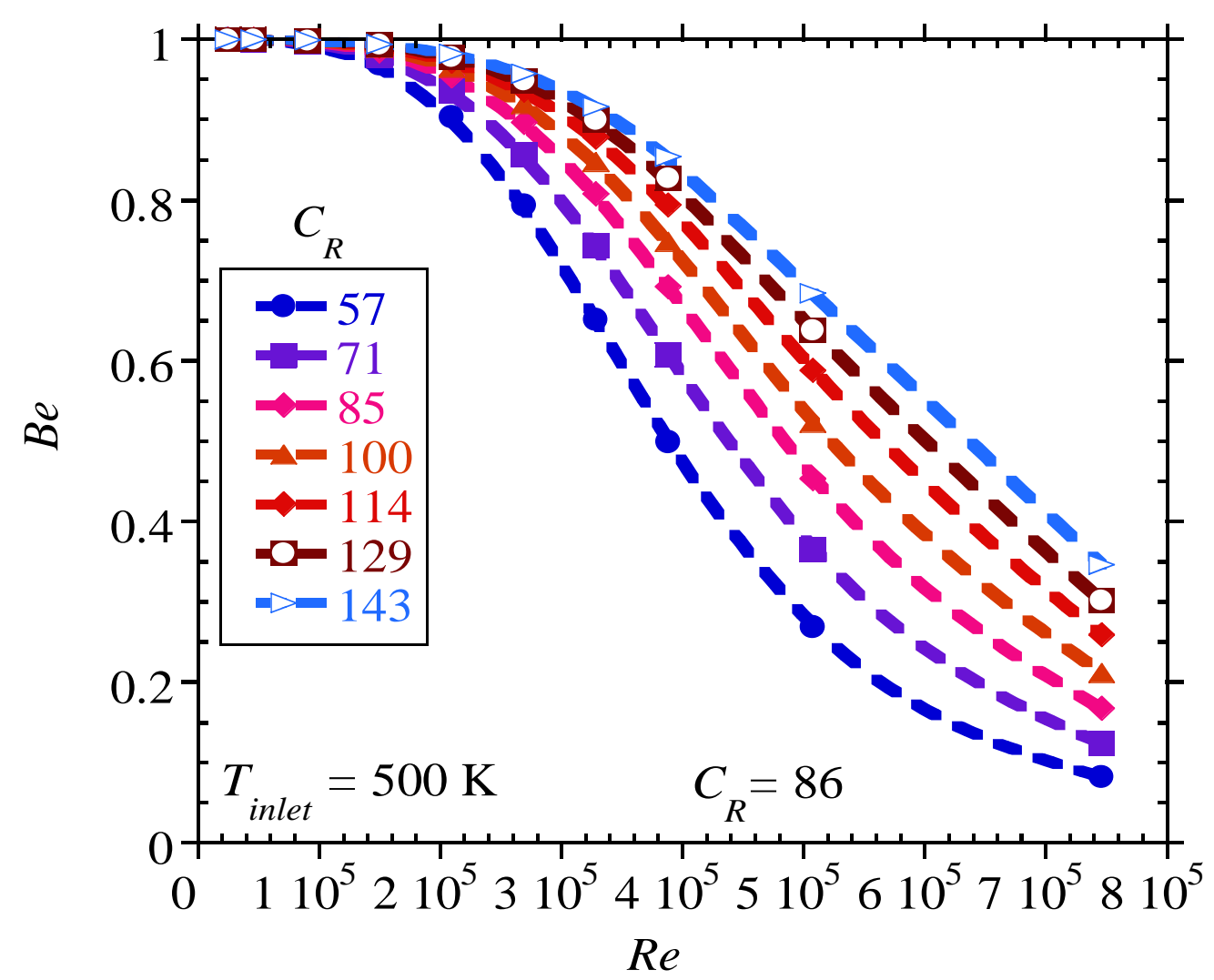

Fig. 18. 
Tables

Table 1.0 Geometrical parameters

\begin{tabular}{cccccc}
\hline \multicolumn{2}{c}{ Reflector } & \multicolumn{2}{c}{ Receiver } & \multicolumn{2}{c}{ Environmental conditions } \\
\hline$a_{c}$ & $4-10 \mathrm{~m}$ & $d_{r i}$ & $0.066 \mathrm{~m}$ & DNI & $1000 \mathrm{~W} / \mathrm{m}^{2}$ \\
$L_{c}$ & $5 \mathrm{~m}$ & $d_{r o}$ & $0.07 \mathrm{~m}$ & $T_{a m b}$ & $300 \mathrm{~K}$ \\
$\rho$ & 0.96 & $d_{g i}$ & $0.11 \mathrm{~m}$ & $V_{w}$ & $2 \mathrm{~m} / \mathrm{s}$ \\
$\varphi_{r}$ & $40-120^{\circ}$ & $\tau_{g}$ & 0.97 & & \\
$C_{R}=A_{c} / A_{r}$ & $57.12-142.86$ & $\tilde{\alpha}$ & 0.96 & & \\
& & $\xi_{g}$ & 0.86 & & \\
\hline
\end{tabular}

Table 2.0: Syltherm 800 thermal properties at $T_{\text {inlet }}=400 \mathrm{~K}, 550 \mathrm{~K}$ and $650 \mathrm{~K}$

\begin{tabular}{cccc}
\hline Thermal property & & $T_{\text {inlet }}(\mathrm{K})$ & \\
& $400 \mathrm{~K}$ & $550 \mathrm{~K}$ & $650 \mathrm{~K}$ \\
\hline Specific heat capacity $\left(c_{p}\right), \mathrm{J} / \mathrm{kg} \mathrm{K}$ & 1791.43 & 2047.318 & 2218.26 \\
Density $(\rho), \mathrm{kg} / \mathrm{m}^{3}$ & 840.06 & 696.0074 & 577.70 \\
Thermal conductivity $(\lambda), \mathrm{W} / \mathrm{m} \mathrm{K}$ & 0.114845 & 0.086661 & 0.067833 \\
Viscosity $(\mu), \mathrm{Pa} . \mathrm{s}$ & 0.002163 & 0.000555 & 0.000284 \\
\hline
\end{tabular}

